\title{
Qualitative and Quantitative Analysis of the Major Constituents in Chinese Medical Preparation Lianhua-Qingwen Capsule by UPLC-DAD-QTOF-MS
}

\author{
Weina Jia, ${ }^{1,2,3}$ Chunhua Wang, ${ }^{1,2,3}$ Yuefei Wang, ${ }^{1,2,3}$ Guixiang Pan, ${ }^{1,2,3}$ Miaomiao Jiang, ${ }^{1,2,3}$ \\ Zheng $\mathrm{Li}^{1,2,3}$ and Yan Zhu ${ }^{1,2,3}$ \\ ${ }^{1}$ Tianjin Key Laboratory of Modern Chinese Medicine, Tianjin University of Traditional Chinese Medicine, Tianjin 300193, China \\ ${ }^{2}$ Tianjin Key Laboratory of TCM Chemistry and Analysis, Tianjin University of Traditional Chinese Medicine, Tianjin 300193, China \\ ${ }^{3}$ Research and Development Center of Traditional Chinese Medicine, Tianjin International Joint Academy of Biotechnology \& Medicine, \\ Tianjin 300457, China
}

Correspondence should be addressed to Yan Zhu; yanzhu.harvard@gmail.com

Received 7 July 2014; Revised 14 August 2014; Accepted 15 August 2014

Academic Editor: Feng Sun

Copyright (c) 2015 Weina Jia et al. This is an open access article distributed under the Creative Commons Attribution License, which permits unrestricted use, distribution, and reproduction in any medium, provided the original work is properly cited.

\begin{abstract}
Lianhua-Qingwen capsule (LQC) is a commonly used Chinese medical preparation to treat viral influenza and especially played a very important role in the fight against severe acute respiratory syndrome (SARS) in 2002-2003 in China. In this paper, a rapid ultraperformance liquid chromatography coupled with diode-array detector and quadrupole time-of-flight mass spectrometry (UPLC-DAD-QTOF-MS) method was established for qualitative and quantitative analysis of the major constituents of LQC. A total of 61 compounds including flavonoids, phenylpropanoids, anthraquinones, triterpenoids, iridoids, and other types of compounds were unambiguously or tentatively identified by comparing the retention times and accurate mass measurement with reference compounds or literature data. Among them, twelve representative compounds were further quantified as chemical markers in quantitative analysis, including salidroside, chlorogenic acid, forsythoside E, cryptochlorogenic acid, amygdalin, sweroside, hyperin, rutin, forsythoside A, phillyrin, rhein, and glycyrrhizic acid. The UPLC-DAD method was evaluated with linearity, limit of detection (LOD), limit of quantification (LOQ), precision, stability, repeatability, and recovery tests. The results showed that the developed quantitative method was linear, sensitive, and precise for the quality control of LQC.
\end{abstract}

\section{Introduction}

Lianhua-Qingwen capsule (LQC), developed from the two classical traditional Chinese medicine (TCM) formulae Maxing-Shigan-Tang and Yinqiao-San which have a long history of clinical application in the treatment of influenza [1], is a commonly used Chinese medical preparation to treat viral influenza and especially played an important role in the fight against severe acute respiratory syndrome (SARS) in 2002-2003 in China [2]. LQC is composed of 11 herbs including Fructus Forsythiae (Lianqiao), Flos Lonicerae Japonicae (Jinyinhua), Herba Ephedrae (Mahuang), Semen Armeniacae Amarum (Kuxingren), Radix Isatidis (Banlangen), Rhizoma Dryopteridis Crassirhizomatis (Mianmaguanzhong), Herba Houttuyniae (Yuxingcao), Herba Pogostemonis
(Guanghuoxiang), Radix et Rhizoma Rhei (Dahuang), Radix et Rhizoma Rhodiolae Crenulatae (Hongjingtian), and Radix et Rhizoma Glycyrrhizae (Gancao), along with menthol and a traditional Chinese mineral medicine, Gypsum Fibrosum (Shigao). According to previous reports, LQC has a good clinical effect on influenza with the symptoms of high fever, aversion to cold, headache, pharyngalgia, cough, sneezing, muscle ache, and so on [3]. Modern pharmacological studies have shown that LQC also has the antiviral, antibacterial, and anti-inflammatory activities $[4,5]$. Recently, the study on its bioactive ingredients and molecular mechanism of action has been gradually reported as well [6].

Although some preliminary analytical methods have been developed for the quality control for LQC, including thin layer chromatography (TLC) [7], high performance 
liquid chromatography (HPLC) $[8,9]$, micellar electrokinetic capillary chromatography (MEKC) [10], and liquid chromatography tandem mass spectrometry (LC-MS/MS) [11], no systematical and comprehensive study on the chemical profiling and quality control method for LQC has been reported so far. For a classical and complex Chinese medical preparation, the comprehensive quality evaluation method should be based on its multiple chemical constituents. Therefore, it is necessary to develop a rapid and sensitive method to identify and quantify the chemical constituents in LQC, which will be beneficial to investigate the effectiveness and evaluate the quality of LQC.

In this study, a reliable, sensitive, and simple ultraperformance liquid chromatography coupled with diode-array detector and quadrupole time-of-flight mass spectrometry (UPLC-DAD-QTOF-MS) method which was more systematical and comprehensive than the earlier ones was established for characterization and quantification of the major chemical constituents of LQC. A total of 61 compounds were unambiguously or tentatively identified by comparing the retention times, exact molecular masses, and MS/MS spectral data with reference compounds or literature data. Furthermore, twenty-seven compounds were confirmed by comparing with the standards. Among them, twelve representative compounds were quantified as chemical markers in quantitative analysis, including salidroside, chlorogenic acid, forsythoside E, cryptochlorogenic acid, amygdalin, sweroside, hyperin, rutin, forsythoside A, phillyrin, rhein, and glycyrrhizic acid. This is the first systematical and comprehensive study on the qualitative and quantitative analysis of LQC.

\section{Experimental}

2.1. Reagents, Chemicals, and Materials. Methanol and acetonitrile (HPLC grade) were purchased from Sigma Aldrich (St. Louis, MO, USA). Formic acid (HPLC grade) was purchased from Tianjin Damao chemical reagent factory (Tianjin, China). Water (HPLC grade) for UPLC analysis was produced by the Milli-Q water purification system (Millipore, USA). Salidroside, chlorogenic acid, forsythoside E, cryptochlorogenic acid, amygdalin, sweroside, hyperin, rutin, forsythoside A, phillyrin, rhein, and glycyrrhizic acid were purchased from Sigma Aldrich (St. Louis, MO, USA). The purity of standard substances was above $98 \%$. Ten batches of LQC were provided by Shijiazhuang Yiling Pharmaceutical Co., Ltd. (Shijiazhuang, China).

2.2. UPLC Analysis. The UPLC analysis was performed on a Waters ACQUITY UPLC instrument (Waters Corporation, MA, USA) coupled with a binary pump, a sample manager, an autosampler, a column compartment, and diode-array detector (DAD). The separation of samples was performed on a Waters ACQUITY UPLC BEH C $18(100 \times 2.1 \mathrm{~mm}, 1.7 \mu \mathrm{m})$ column with the column temperature at $50^{\circ} \mathrm{C}$. The analysis was completed in $30 \mathrm{~min}$ with a gradient elution of $0.1 \%$ formic acid aqueous solution (A) and methanol (B) at the flow rate of $0.3 \mathrm{~mL} / \mathrm{min}$. The gradient program was designed as follows: $0-11 \mathrm{~min}, 5-35 \% \mathrm{~B}$; $11-18 \mathrm{~min}, 35-55 \% \mathrm{~B} ; 18-22 \mathrm{~min}$, $55-75 \%$ B; 22-24 min, 75-90\% B; 24-25 min, 90-100\% B; and $25-30 \mathrm{~min}, 100 \% \mathrm{~B}$. The injection volume was $5 \mu \mathrm{L}$. The detection wavelengths of DAD were set at $210 \mathrm{~nm}, 225 \mathrm{~nm}$, and $254 \mathrm{~nm}$.

2.3. UPLC-DAD-QTOF-MS Analysis. The Waters ACQUITY UPLC instrument (Waters, MA, USA) coupled with Waters Synapt HDMS G1 (Waters, Manchester, UK) via an electrospray ionization (ESI) interface. The UPLC analytical conditions were the same as the UPLC analysis described above. The full scan mass spectra data were acquired in positive and negative ion modes. Acquisition parameters are as follows: capillary voltage was $3000 \mathrm{~V}$ for ESI (+) and $2600 \mathrm{~V}$ for ESI (-); cone voltage was $45 \mathrm{~V}$; the ESI source temperature was $100^{\circ} \mathrm{C}$; the desolvation temperature was $350^{\circ} \mathrm{C}$; the nitrogen $\left(\mathrm{N}_{2}\right)$ was used as desolvation gas at flow rates of $600 \mathrm{~L} / \mathrm{h}$ for both ESI (+) and ESI (-); and the range of full scan was set at $\mathrm{m} / z 150-$ $1000 \mathrm{Da}$. The version of analysis software was Mass Lynx V4.1.

2.4. Sample and Standard Solutions Preparation. The powder of LQC ( $0.4 \mathrm{~g})$ was accurately weighed and extracted with $60 \%$ methanol-water $(\mathrm{v} / \mathrm{v})$ solution $(20 \mathrm{~mL})$ in an ultrasonic water bath for $30 \mathrm{~min}$ at room temperature. The supernatant solution was diluted with the same amount of water and then centrifuged for $10 \mathrm{~min}$ at $14,000 \mathrm{r} / \mathrm{min}$. All the obtained solutions were filtered through $0.22 \mu \mathrm{m}$ syringe filter before the UPLC analysis.

Twelve standards were accurately weighed and dissolved in methanol to obtain stock solutions, respectively. A mixed stock solution of standards was prepared by adding a suitable volume of each stock solution to a $5 \mathrm{~mL}$ flask and diluted with $30 \%$ methanol-water solution at the concentration of $67.8 \mu \mathrm{g} / \mathrm{mL}$ for salidroside, $109.65 \mu \mathrm{g} / \mathrm{mL}$ for chlorogenic acid, $77.64 \mu \mathrm{g} / \mathrm{mL}$ for forsythoside E, $106.47 \mu \mathrm{g} / \mathrm{mL}$ for cryptochlorogenic acid, $62.57 \mu \mathrm{g} / \mathrm{mL}$ for amygdalin, $31.96 \mu \mathrm{g} / \mathrm{mL}$ for sweroside, $3.21 \mu \mathrm{g} / \mathrm{mL}$ for hyperin, $8.5 \mu \mathrm{g} / \mathrm{mL}$ for rutin, $67.34 \mu \mathrm{g} / \mathrm{mL}$ for forsythoside $\mathrm{A}, 45.71 \mu \mathrm{g} / \mathrm{mL}$ for phillyrin, $55.49 \mu \mathrm{g} / \mathrm{mL}$ for rhein, and $84.35 \mu \mathrm{g} / \mathrm{mL}$ for glycyrrhizic acid, respectively. The mixed stock solution was then serially diluted with $30 \%$ methanol-water solution to obtain five appropriate concentrations used for plotting standard curves. The lowest concentration of the mixture stock solution was further diluted to give a series of different concentrations for investigating the limits of detection (LODs) and limits of quantification (LOQs) of the 12 chemical constituents. All solutions were stored at $4^{\circ} \mathrm{C}$ until analysis.

2.5. Validation of the Quantitative Analysis. The UPLC-DAD method was evaluated with linearity, LOD, LOQ, precision, stability, repeatability, and recovery tests. The calibration curves were constructed with five different concentrations of chemical markers in triplicate. The LODs and LOQs were measured under the UPLC analytical conditions at a signalto-noise $(\mathrm{S} / \mathrm{N})$ ratio of 3 and 10 , respectively. For intraday 
TABLE 1: Quantitative results of 12 compounds in LQC extracted by different methods.

\begin{tabular}{|c|c|c|c|c|c|c|c|c|c|}
\hline \multirow{4}{*}{ Content $(\mu \mathrm{g} / \mathrm{g})$} & \multicolumn{9}{|c|}{ Methods } \\
\hline & $30 \%^{\mathrm{a}}$ & $60 \%$ & $90 \%$ & $60 \%$ & $60 \%$ & $60 \%$ & $60 \%$ & $60 \%$ & $60 \%$ \\
\hline & $30 \min ^{\mathrm{b}}$ & $30 \mathrm{~min}$ & $30 \mathrm{~min}$ & $30 \mathrm{~min}$ & $30 \mathrm{~min}$ & $30 \mathrm{~min}$ & $15 \mathrm{~min}$ & $30 \mathrm{~min}$ & $45 \mathrm{~min}$ \\
\hline & $1: 100^{\mathrm{c}}$ & $1: 100$ & $1: 100$ & $1: 50$ & $1: 100$ & $1: 200$ & $1: 100$ & $1: 100$ & $1: 100$ \\
\hline Salidroside & 1726.28 & 1701.25 & 1622.02 & 1522.31 & 1701.25 & 1656.32 & 1711.54 & 1701.25 & 1688.54 \\
\hline Chlorogenic acid & 2444.97 & 2492.15 & 2216.89 & 2285.43 & 2492.15 & 2289.27 & 2492.62 & 2492.15 & 2552.17 \\
\hline Forsythoside E & 1583.93 & 1620.78 & 451.91 & 1462.09 & 1620.78 & 1402.53 & 1627.01 & 1620.78 & 1579.63 \\
\hline Cryptochlorogenic acid & 1862.98 & 1851.64 & 667.50 & 1703.05 & 1851.64 & 1771.79 & 1837.89 & 1851.64 & 1857.95 \\
\hline Amygdalin & 1424.11 & 1455.39 & 1442.56 & 1268.93 & 1455.39 & 1298.11 & 1395.97 & 1455.39 & 1431.38 \\
\hline Sweroside & 816.19 & 813.18 & 789.32 & 747.06 & 813.18 & 772.67 & 812.51 & 813.18 & 808.24 \\
\hline Hyperin & 135.10 & 151.73 & 167.26 & 140.84 & 151.73 & 140.80 & 152.72 & 151.73 & 157.67 \\
\hline Rutin & 122.00 & 121.17 & 115.22 & 106.11 & 121.17 & 116.67 & 117.09 & 121.17 & 116.62 \\
\hline Forsythoside A & 2484.60 & 2536.34 & 2661.79 & 2285.76 & 2536.34 & 2396.35 & 2543.87 & 2536.34 & 2521.10 \\
\hline Phillyrin & 1660.26 & 1521.45 & 1551.59 & 1410.19 & 1521.45 & 1390.12 & 1523.01 & 1521.45 & 1551.52 \\
\hline Rhein & 803.13 & 1102.06 & 1370.11 & 937.63 & 1102.06 & 932.05 & 956.38 & 1102.06 & 1054.77 \\
\hline Glycyrrhizic acid & 1530.49 & 1680.43 & 1594.37 & 1437.40 & 1680.43 & 1619.99 & 1674.81 & 1680.43 & 1665.42 \\
\hline
\end{tabular}

${ }^{a}$ Extracting solvent: 30\%, 60\%, and 90\% methanol-water solution.

${ }^{\mathrm{b}}$ Ultrasonic time: $15 \mathrm{~min}, 30 \mathrm{~min}$, and $45 \mathrm{~min}$.

${ }^{c}$ Extraction solvent multiples: 1:50,1:100, and 1:200 expressed 50, 100, and 200 times per gram of sample.

and interday precisions test, the samples were analyzed by six repetitive injections within one day and once a day for three successive days, respectively. At room temperature, the stability of sample solution was evaluated by replicate injection at $0,1,2,4,6,8,10,14,24$, and $48 \mathrm{~h}$. In order to check the repeatability, six samples from the same source were investigated. Accurate amounts of the reference standards were added to $0.20 \mathrm{~g}$ powder of sample in sextuplicate. The resultant sample solutions were then extracted and quantified with the described method. The relative standard deviation (RSD) was used to evaluate the results.

\section{Results and Discussion}

3.1. Optimization of the Extraction and Chromatographic Conditions. A single-factor method was used to investigate the extraction effect of the extraction solvent $(30 \%, 60 \%$, and $90 \%$ methanol-water solution), extraction solvent ratio $(1: 50,1: 100$, and $1: 200(\mathrm{w} / \mathrm{v}))$, and extraction time (15 min, $30 \mathrm{~min}$, and $45 \mathrm{~min}$ ), respectively. By analyzing the extraction efficiency, $60 \%$ methanol-water solution, extraction solvent ratio at $1: 100$, and $30 \mathrm{~min}$ of ultrasonic time were selected as the eventual extraction conditions. The results are described in Table 1.

Due to the existence of acidic constituents in sample solutions, formic acid was added into the mobile phase which could inhibit the ionization of these acidic ingredients to improve the peak shape. The mobile phase systems (methanol-formic acid aqueous solution and acetonitrileformic acid aqueous solution) and column temperature $\left(40^{\circ} \mathrm{C}\right.$ and $50^{\circ} \mathrm{C}$ ) were investigated, which showed that methanol$0.1 \%$ formic acid aqueous solution as mobile phase with column temperature at $50^{\circ} \mathrm{C}$ could obtain the best chromatographic peak shape. Because the maximum absorptions of 12 reference compounds were different, three detection wavelengths were finally selected in order to achieve the goal of high detection sensitivity and little interference. Forsythoside E (peak 7), cryptochlorogenic acid (peak 9), amygdalin (peak 33), and phillyrin (peak 39) had satisfactory sensitivity at $210 \mathrm{~nm}$, salidroside (peak 6), chlorogenic acid (peak 8), and rhein (peak 54) at $225 \mathrm{~nm}$, and sweroside (peak 13), hyperin (peak 26), rutin (peak 29), forsythoside A (peak 30), and glycyrrhizic acid (peak 57) at $254 \mathrm{~nm}$. The chromatograms are presented in Figure 1.

3.2. UPLC-DAD-QTOF-MS Analysis of Reference Compounds and LQC Samples. As shown in Table 2, a total of 61 compounds were unambiguously or tentatively identified by comparing the retention times and accurate mass measurement with references or literature data. These compounds were divided into six types according to their structural characteristics including flavonoids, phenylpropanoids, anthraquinones, triterpenoids, iridoids, and other types. The structures of identified compounds are listed in Figure 3. Among them, twenty-seven compounds were further confirmed by comparing with standards. The total ion chromatograms are shown in Figure 2.

3.2.1. Flavonoids. Seventeen flavonoids (Figure 3(a)) in LQC including flavone aglycones and glycosides were identified. They were mainly obtained from Lianqiao, Jinyinhua, Gancao, Hongjingtian, and Mahuang. Amongst them, liquiritin apioside (22), ononin (25), hyperin (26), rutin (29), liquiritigenin (35), isoliquiritin apioside (36), isoliquiritin (37), and 




(a)

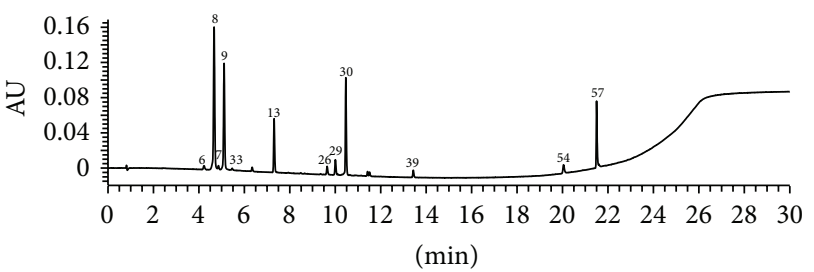

(c)

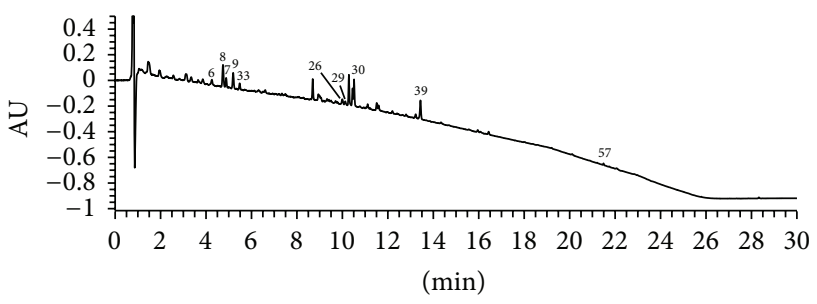

(e)

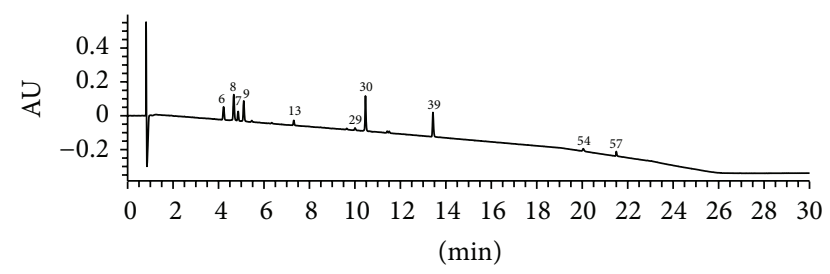

(b)



(d)

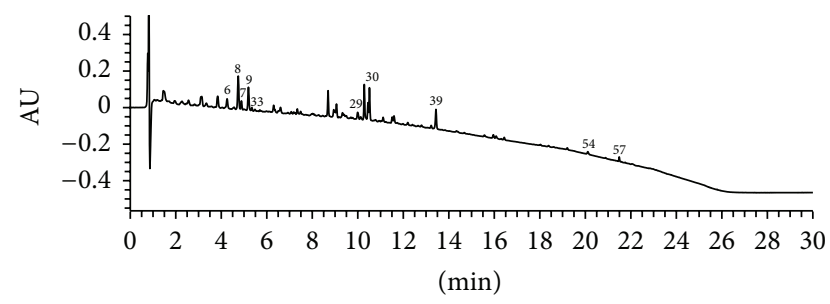

(f)

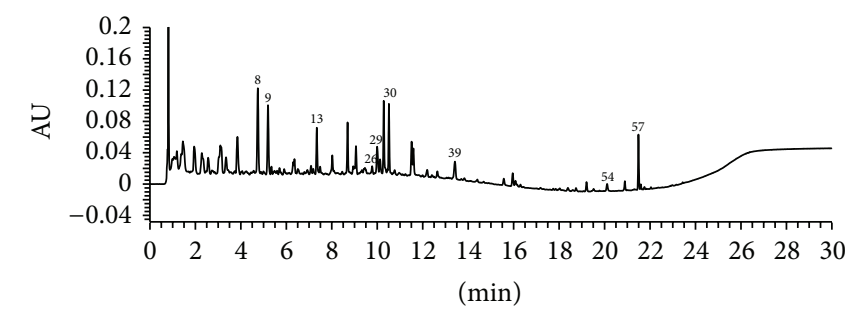

(g)

FIGURE 1: UPLC-DAD chromatograms of standard solution of $210 \mathrm{~nm}$ (a), $225 \mathrm{~nm}$ (b), $254 \mathrm{~nm}$ (c), negative sample solution (d), and sample solution of $210 \mathrm{~nm}(\mathrm{e}), 225 \mathrm{~nm}(\mathrm{f})$, and $254 \mathrm{~nm}$ (g).
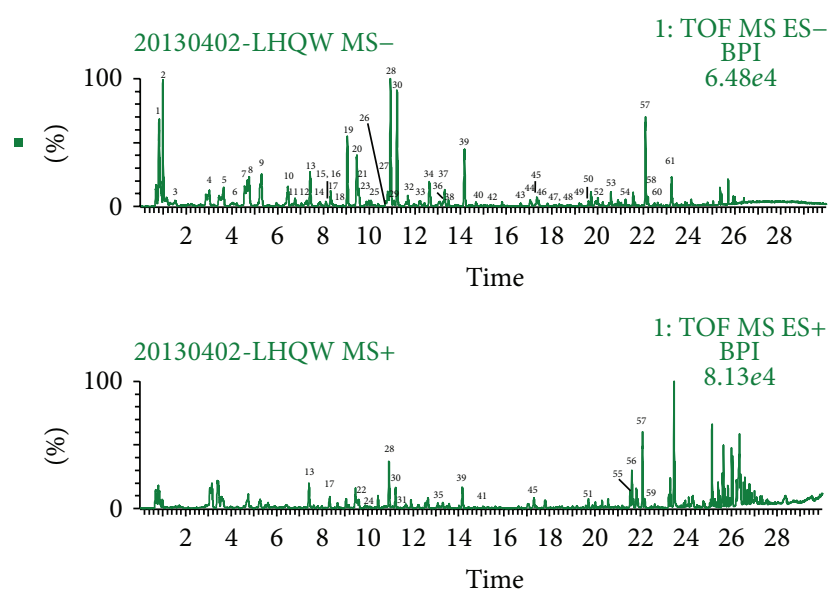

FIGURE 2: UPLC-QTOF-MS chromatograms of sample solution from negative ion mode and positive ion mode. formononetin (47) were unambiguously identified via the standards.

In negative and positive ion modes, flavone aglycones mainly gain fragment ions by the reverse Diels-Alder (RDA) reaction and the loss of $\mathrm{CO}(28 \mathrm{Da})$. The characteristic fragmentation behavior of compound 35 is shown in Figure 4(a) with high abundant fragmentation [M+H-VP (4vinylphenol) $]^{+}$at $m / z 137.0422$. The abundance of fragment ions $\left[\mathrm{M}+\mathrm{H}-\mathrm{RL}(\text { resorcinol) }]^{+}\right.$at $\mathrm{m} / z 147.0621$ and $[\mathrm{M}+\mathrm{H}-$ $\mathrm{RL}-\mathrm{CO}]^{+}$at $m / z 119.0691$ is relatively lower. Compounds 24, 40, 42, and 46 were tentatively identified via comparing their exact molecular masses, MS/MS spectra data, and retention behaviors with literature data $[13,26,39]$. Flavone glycosides have the similar fragmentation pathways of simultaneous or successive loss of glucose (162 Da), rhamnose (146 Da), or apiose $(132 \mathrm{Da})$. The fragmentation pathway of compound 26 was exemplified in Figure 4(b) in negative ion mode. Compounds 21, 23, 31, 41, and 53 were tentatively identified 


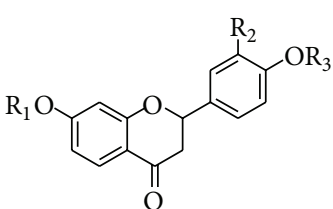

$21 \mathrm{R}_{1}=\mathrm{H}, \mathrm{R}_{2}=\mathrm{H}, \mathrm{R}_{3}=\mathrm{Glc}$

$22 \mathrm{R}_{1}=\mathrm{H}, \mathrm{R}_{2}=\mathrm{H}, \mathrm{R}_{3}=\mathrm{Glc}(2 \rightarrow 4) \mathrm{Api}$

$35 \mathrm{R}_{1}=\mathrm{H}, \mathrm{R}_{2}=\mathrm{H}, \mathrm{R}_{3}=\mathrm{H}$

$41 \mathrm{R}_{1}=$ Glc $(6 \rightarrow 1)$ Rha, $\mathrm{R}_{2}=\mathrm{OH}, \mathrm{R}_{3}=\mathrm{CH}_{3}$<smiles>[R20]Oc1cc(O)c2c(=O)c([R])c(-c3cc([R6])c(O)c([R])c3)oc2c1[R]</smiles>

$24 \mathrm{R}_{1}=\mathrm{OH}, \mathrm{R}_{2}=\mathrm{Rha}(3 \rightarrow 1) \mathrm{Glc}, \mathrm{R}_{3}=\mathrm{OH}, \mathrm{R}_{4}=\mathrm{H}, \mathrm{R}_{5}=\mathrm{H}$ $26 \mathrm{R}_{1}=$ OGlc, $\mathrm{R}_{2}=\mathrm{H}, \mathrm{R}_{3}=\mathrm{H}, \mathrm{R}_{4}=\mathrm{H}, \mathrm{R}_{5}=\mathrm{OH}$

$29 \mathrm{R}_{1}=$ OGlc $(6 \rightarrow 1)$ Rha, $\mathrm{R}_{2}=\mathrm{H}, \mathrm{R}_{3}=\mathrm{H}, \mathrm{R}_{4}=\mathrm{OH}, \mathrm{R}_{5}=\mathrm{H}$

$31 \mathrm{R}_{1}=$ OGlc $(6 \rightarrow 1)$ Rha, $\mathrm{R}_{2}=\mathrm{H}, \mathrm{R}_{3}=\mathrm{H}, \mathrm{R}_{4}=\mathrm{H}, \mathrm{R}_{5}=\mathrm{H}$

$40 \mathrm{R}_{1}=\mathrm{OH}, \mathrm{R}_{2}=\mathrm{H}, \mathrm{R}_{3}=\mathrm{H}, \mathrm{R}_{4}=\mathrm{H}, \mathrm{R}_{5}=\mathrm{OH}$

$42 \mathrm{R}_{1}=\mathrm{OH}, \mathrm{R}_{2}=\mathrm{H}, \mathrm{R}_{3}=\mathrm{H}, \mathrm{R}_{4}=\mathrm{H}, \mathrm{R}_{5}=\mathrm{H}$

$53 \mathrm{R}_{1}=\mathrm{H}, \mathrm{R}_{2}=\mathrm{H}, \mathrm{R}_{3}=\mathrm{H}, \mathrm{R}_{4}=\mathrm{OCH}_{3}, \mathrm{R}_{5}=\mathrm{OCH}_{3}$<smiles>[R1]c1cc(O)cc([R])c1C(=O)/C=C/c1ccc(C(C)(C)C)cc1</smiles>

$36 \mathrm{R}_{1}=\mathrm{OH}, \mathrm{R}_{2}=\mathrm{H}, \mathrm{R}_{3}=\mathrm{Glc}(2 \rightarrow 4) \mathrm{Api}$

$37 \mathrm{R}_{1}=\mathrm{H}, \mathrm{R}_{2}=\mathrm{OH}, \mathrm{R}_{3}=\mathrm{Glc}$

$46 \mathrm{R}_{1}=\mathrm{H}, \mathrm{R}_{2}=\mathrm{OH}, \mathrm{R}_{3}=\mathrm{H}$<smiles>[R]Oc1ccc2c(=O)c(-c3ccc(OC)cc3)coc2c1</smiles>

$25 \mathrm{R}=\mathrm{Glc}$

$47 \mathrm{R}=\mathrm{H}$

(a)<smiles>O=C(/C=C/c1ccc(O)c(O)c1)OC1C[C@](O)(C(=O)O)C[C@H](O)C1O</smiles>

4<smiles>O=C(/C=C/c1ccc(O)c(O)c1)O[C@@H]1C[C@](O)(C(=O)O)C[C@H](O)[C@H]1O</smiles>

8<smiles>O=C(/C=C/c1ccc(O)c(O)c1)OC1C(O)[C@H](O)C(O)(C(=O)O)C[C@H]1O</smiles>

9

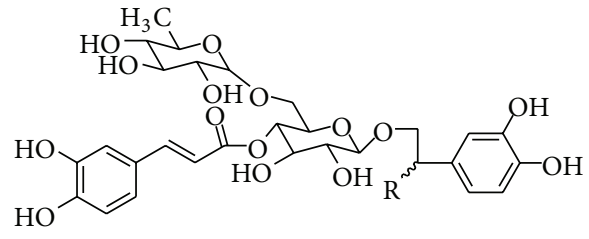

$16 / 18 \mathrm{R}=\mathrm{OH}$<smiles>[2H][C@@]1(C(=O)O)CC(OC(=O)/C=C/c2ccc(O)c(O)c2)C(O)[C@@H](OC(=O)/C=C/c2ccc(O)c(O)c2)C1</smiles>

27

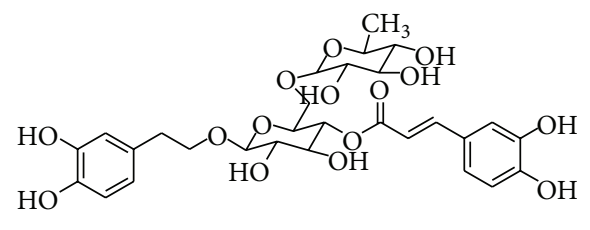

30<smiles>O=C(/C=C/c1cc(O)cc(O)c1)O[C@H]1C[C@@](O)(C(=O)O)C[C@H](O)[C@H]1OC(=O)/C=C/c1ccc(O)c(O)c1</smiles>

34

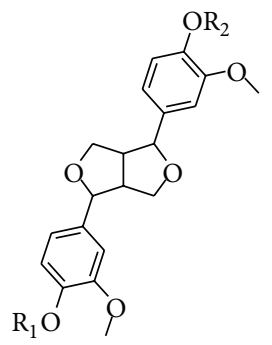

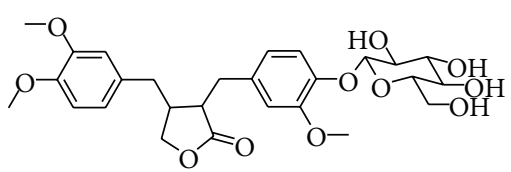

38

(b)<smiles>COc1c(CC=C(C)C)c(O)cc2oc(=O)c(-c3ccc(O)cc3O)cc12</smiles>

56

$32 \mathrm{R}_{1}=\mathrm{Glc}, \mathrm{R}_{2}=\mathrm{H}$

$39 \mathrm{R}_{1}=\mathrm{Glc}, \mathrm{R}_{2}=\mathrm{CH}_{3}$<smiles>[R]Oc1cc([R])cc2c1C(=O)c1c(O[R20])cc([R])cc1C2=O</smiles>

$17 \mathrm{R}_{1}=\mathrm{Glc}, \mathrm{R}_{2}=\mathrm{CH}_{3}, \mathrm{R}_{3}=\mathrm{H}, \mathrm{R}_{4}=\mathrm{H}$

$43 \mathrm{R}_{1}=\mathrm{H}, \mathrm{R}_{2}=\mathrm{CH}_{3}, \mathrm{R}_{3}=\mathrm{H}, \mathrm{R}_{4}=\mathrm{H}$

$45 \mathrm{R}_{1}=\mathrm{H}, \mathrm{R}_{2}=\mathrm{CH}_{3}, \mathrm{R}_{3}=\mathrm{OH}, \mathrm{R}_{4}=\mathrm{Glc}$

$49 \mathrm{R}_{1}=\mathrm{H}, \mathrm{R}_{2}=\mathrm{CH}_{3}, \mathrm{R}_{3}=\mathrm{OCH}_{3}, \mathrm{R}_{4}=\mathrm{Glc}$

$54 \mathrm{R}_{1}=\mathrm{H}, \mathrm{R}_{2}=\mathrm{COOH}, \mathrm{R}_{3}=\mathrm{H}, \mathrm{R}_{4}=\mathrm{H}$

$61 \mathrm{R}_{1}=\mathrm{H}, \mathrm{R}_{2}=\mathrm{CH}_{3}, \mathrm{R}_{3}=\mathrm{OH}, \mathrm{R}_{4}=\mathrm{H}$

(c)

FIgURE 3: Continued. 


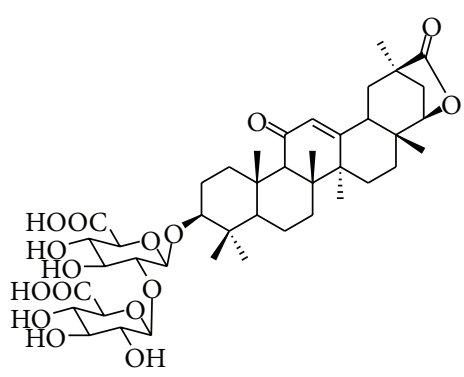

50

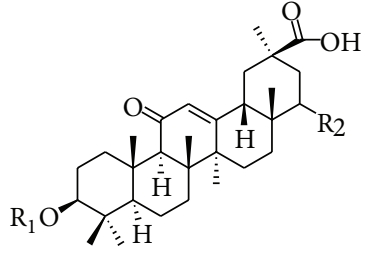

$52 \mathrm{R}_{1}=$ GlcA $(2 \rightarrow 1)$ GlcA, $\mathrm{R}_{2}=$ acetoxy $57 \mathrm{R}_{1}=$ GlcA $(2 \rightarrow 1)$ GlcA, $\mathrm{R}_{2}=\mathrm{H}$

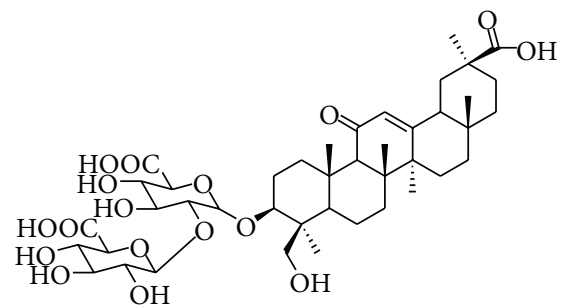

55



58

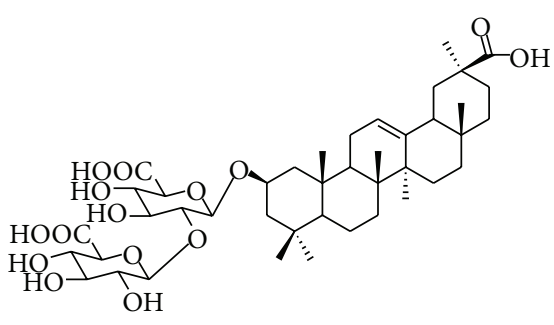

59

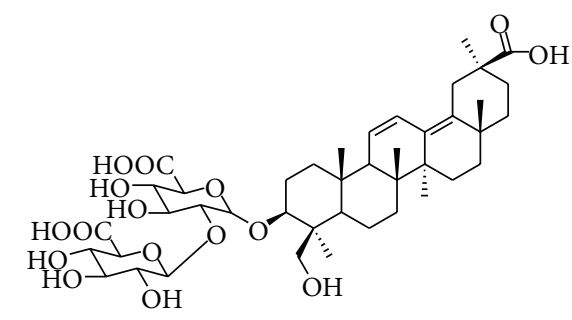

60

(d)

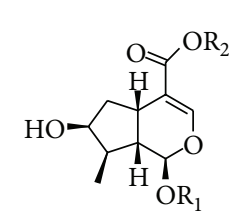

$5 \mathrm{R}_{1}=\mathrm{Glc}, \mathrm{R}_{2}=\mathrm{H}$

$10 \mathrm{R}_{1}=\mathrm{Glc}, \mathrm{R}_{2}=\mathrm{CH}_{3}$



13

20

(e)<smiles>O=C(O)C1(O)CC(O)C(O)C(O)C1O</smiles>

1<smiles>O=C(O)CC(O)(CC(=O)O)C(=O)O</smiles>

2<smiles>O=C(O)c1cc(O)c(O)c(O)c1</smiles>

3<smiles>OCC1OC2OC(O)C(O)C(O)C1C(O)C2O</smiles>

6



7



11

15

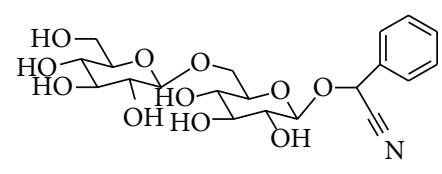

33<smiles>CC(O)CCc1ccc(OC2OC3CCOC(CO)C(O)C(O)C3O2)cc1</smiles>

51

(f)

FIGURE 3: Chemical structures of the compounds identified from LQC (except for the 7 isomers).

by comparing the molecular mass and MS/MS data with literature data $[25,45]$.

3.2.2. Phenylpropanoids. Fourteen phenylpropanoids (Figure 3(b)) including phenylpropionic acids, lignans, and coumarins were identified in LQC. They were mainly obtained from Lianqiao, Jinyinhua, and Gancao. Neochlorogenic acid
(4), chlorogenic acid (8), cryptochlorogenic acid (9), 3,5dicaffeoylquinic acid (27), forsythoside A (30), 3,4-dicaffeoylquinic acid (34), and phillyrin (39) were unambiguously characterized by comparing with standards.

In negative ion mode, phenylpropionic acids have the similar fragmentation pathways of simultaneous or successive loss of $\mathrm{H}_{2} \mathrm{O}(18 \mathrm{Da}), \mathrm{CO}(28 \mathrm{Da})$, and $\mathrm{CO}_{2}(44 \mathrm{Da})$. 

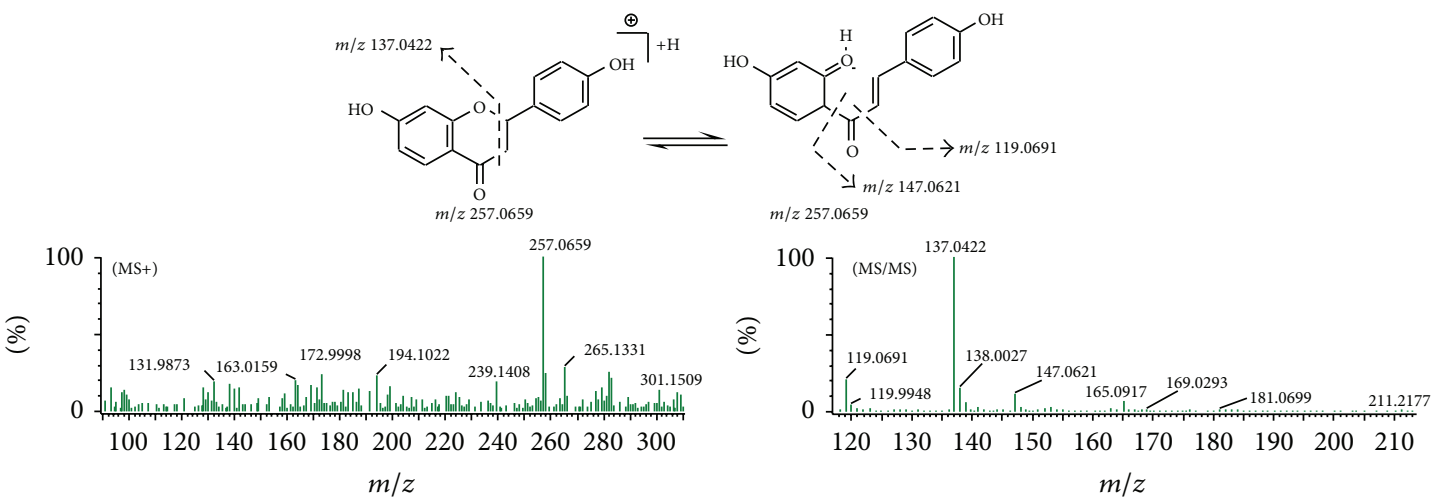

(a)

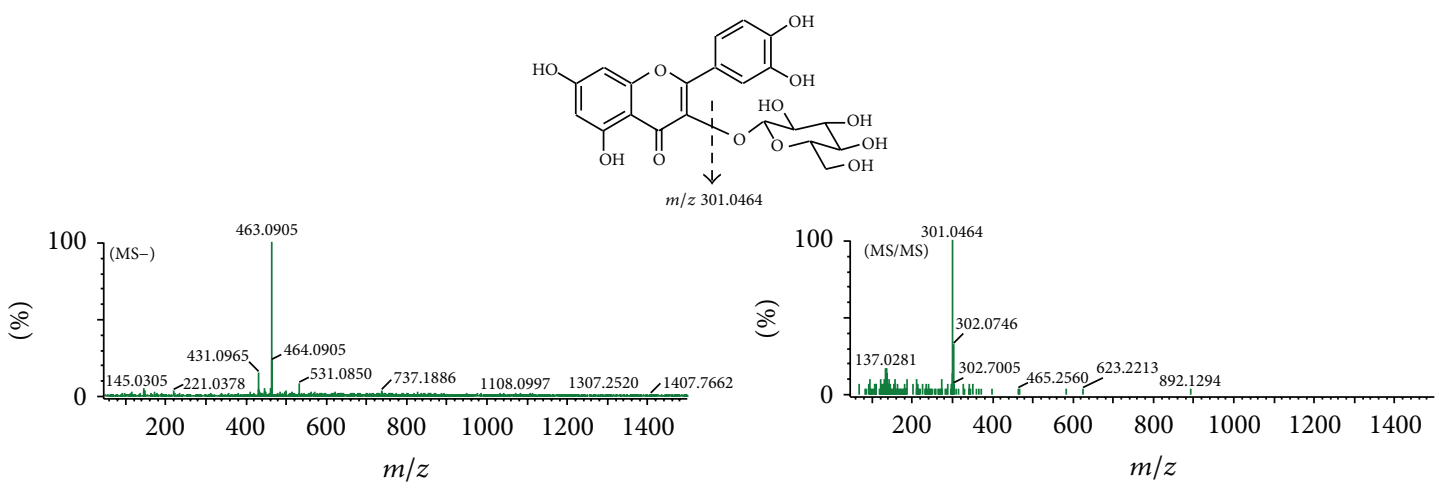

(b)

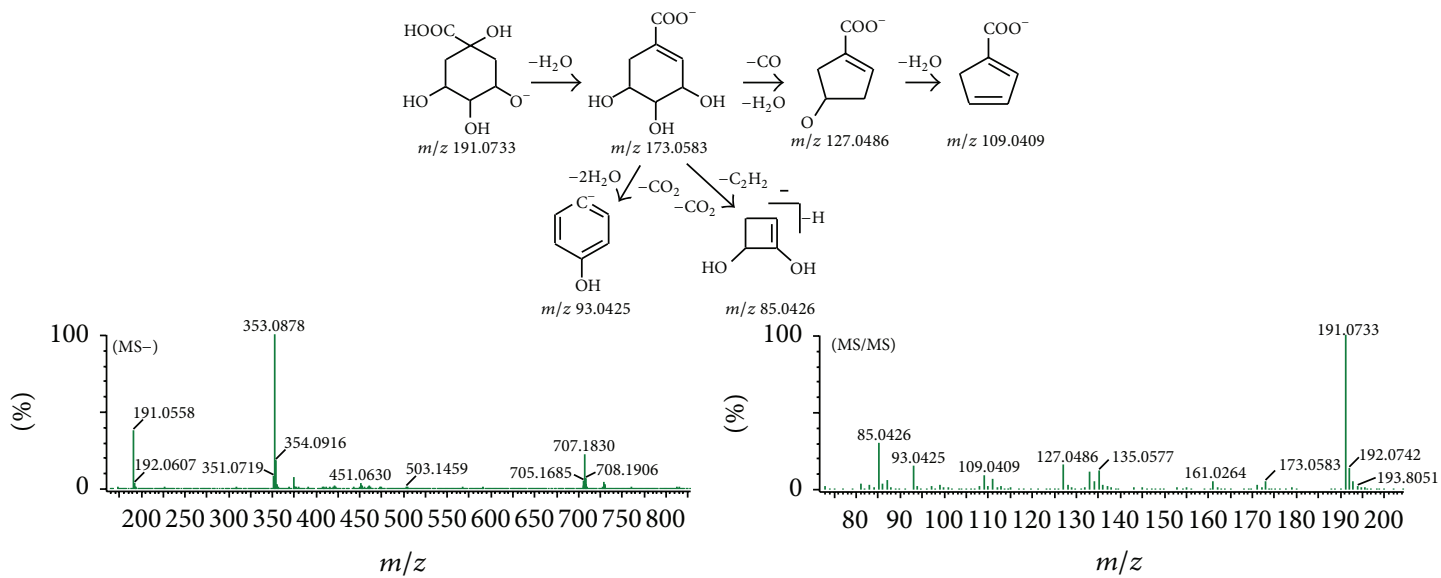

(c)
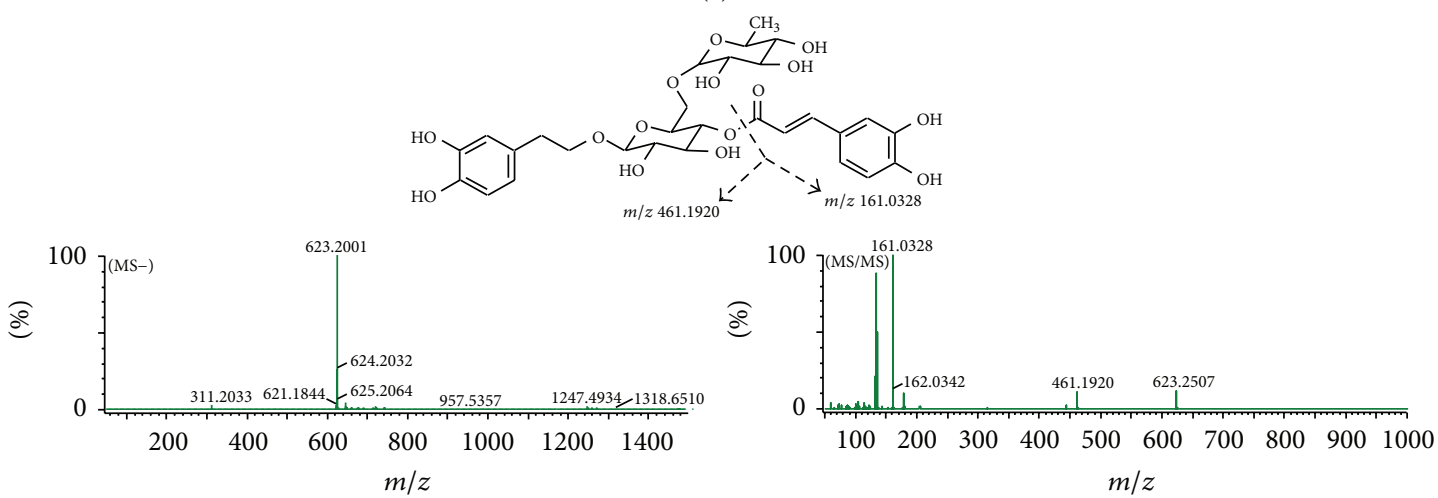

(d)

Figure 4: Continued. 


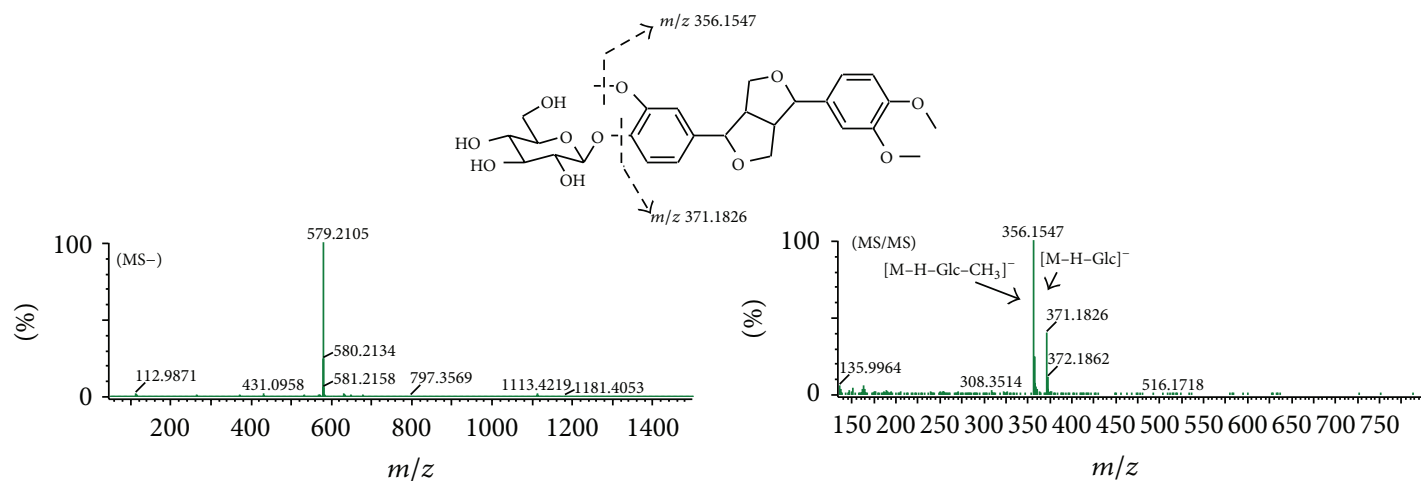

(e)

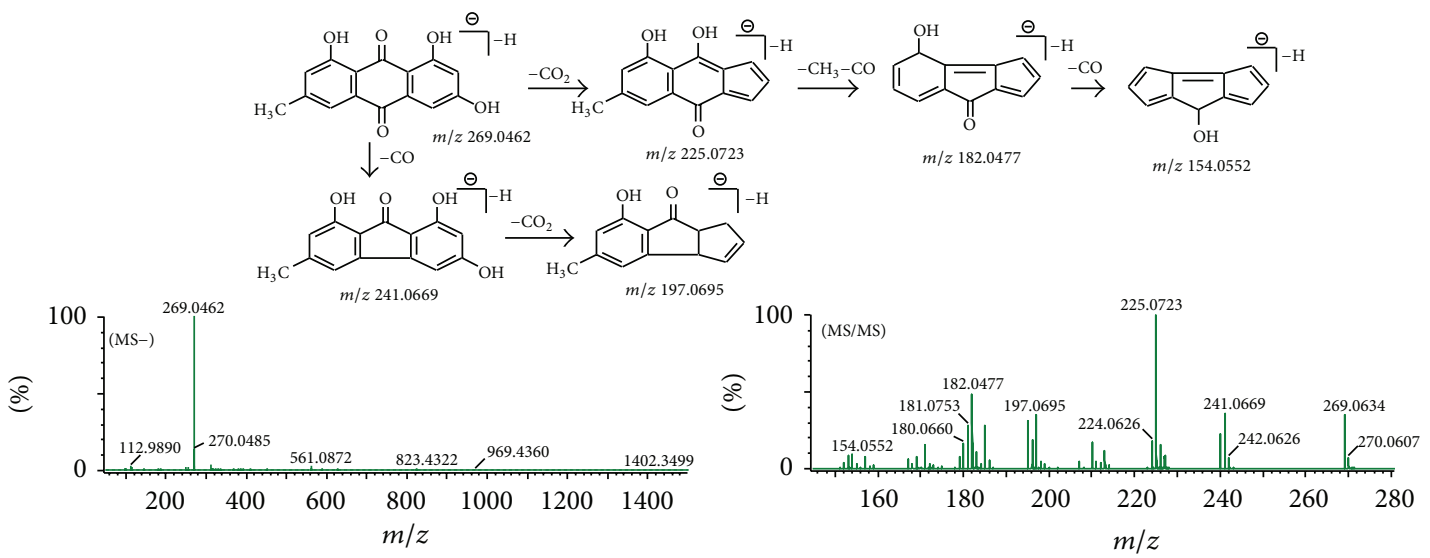

(f)

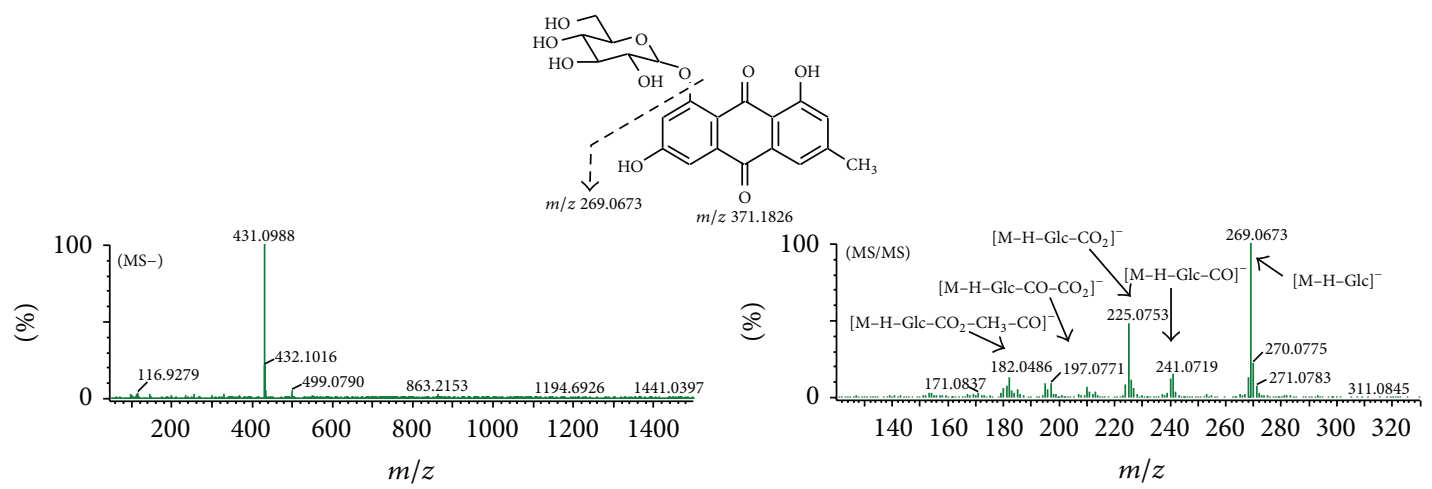

(g)

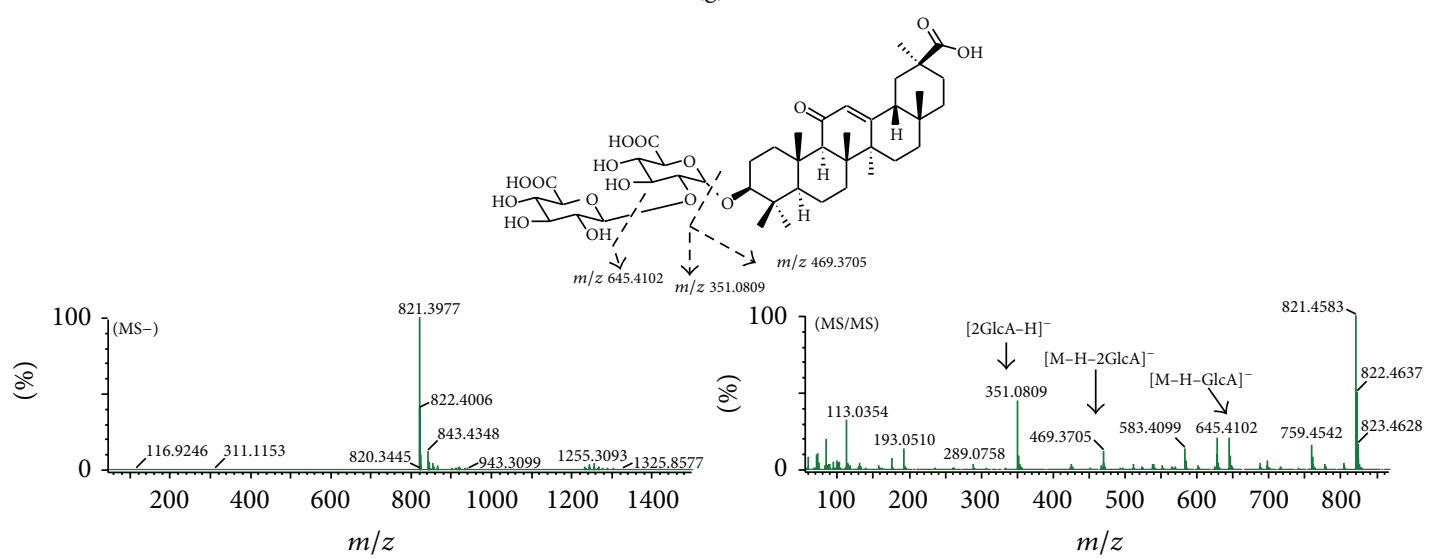

(h)

Figure 4: Continued. 


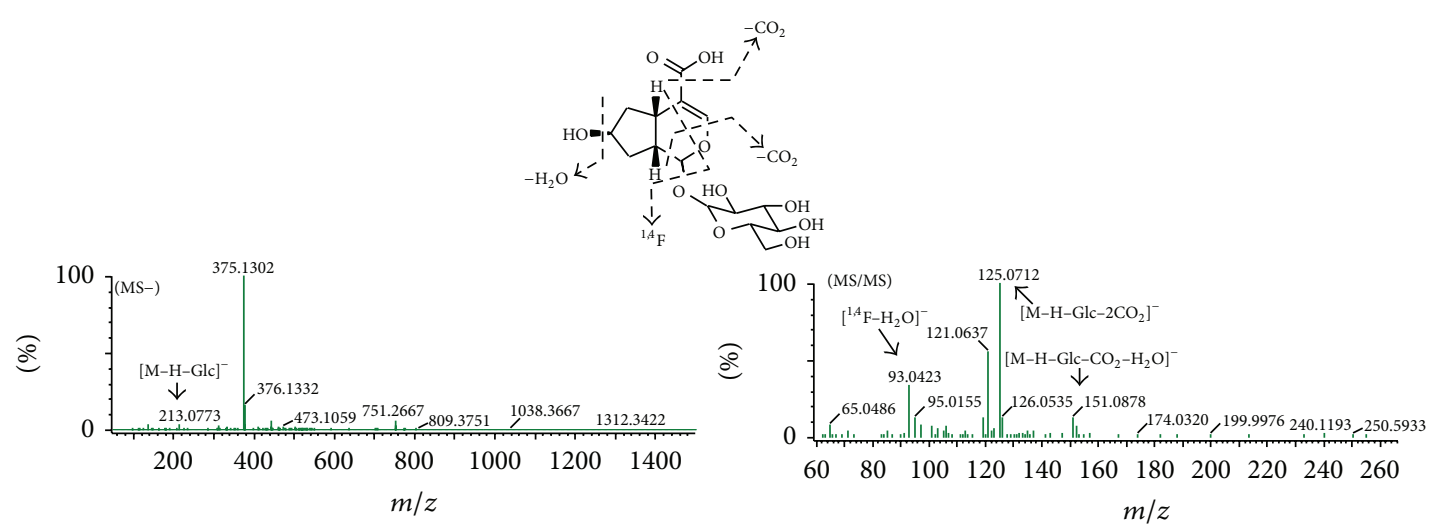

(i)

FIGURE 4: The MS spectra and fragmentation pathway of compound $\mathbf{3 5}$ (a), compound $\mathbf{2 6}$ (b), compound $\mathbf{8}$ (c), compound $\mathbf{3 0}$ (d), compound 39 (e), compound 61 (f), compound 45 (g), compound 57 (h), and compound 5 (i).

The fragmentation pathway of compound 8 [18], as the representative of phenylpropionic acids, is shown in Figure 4(c). Compound 30 produced [M-H-Ca (caffeoyl) $]^{-}$at $\mathrm{m} / z$ 461.1920 and [Caffeic- $\left.\mathrm{H}_{-} \mathrm{H}_{2} \mathrm{O}\right]^{-}$at $m / z$ 161.0328, as displayed in Figure $4(\mathrm{~d})$. Lignans primarily generated $[\mathrm{M}+\mathrm{HCOO}]^{-}$ in negative ion mode and further elimination of glucose (162 Da) produced aglycone. As shown in Figure 4(e), compound 39 produced characteristic fragments at $\mathrm{m} / z 371.1826$ and $m / z 356.1547$ corresponding to [M-H-Glc (glucose) ] and $\left[\mathrm{M}-\mathrm{H}-\mathrm{Glc}-\mathrm{CH}_{3}\right]^{-}$, respectively. Compounds 16, 18, 19, $\mathbf{2 8}, 32,38$, and 56 were tentatively identified on the basis of the exact molecular formulae matching, fragmentation information, and retention behaviors as well as literature data $[23,24,33,36,47]$.

3.2.3. Anthraquinones. Eight anthraquinones (Figure 3(c)) in LQC were definitely or tentatively identified. All of them were derived from Dahuang. Chrysophanol glucoside (17), emodin-8-O-glucoside (45), rhein (54), and emodin (61) were confirmed via comparing with standard substances.

The characteristic fragmentation behavior of anthraquinones was the loss of $\mathrm{CO}_{2}(44 \mathrm{Da}), \mathrm{CH}_{3}(15 \mathrm{Da})$, and CO $(28 \mathrm{Da})$ in negative ion mode. Typical compound $\mathbf{6 1}$ was used to explain the fragmentation pathway of anthraquinones presented in Figure $4(\mathrm{f})$. Compound 45, as shown in Figure 4(g), produced characteristic fragments at $\mathrm{m} / z$ 269.0673, $\mathrm{m} / z$ 241.0719, $\mathrm{m} / z$ 225.0753, $\mathrm{m} / z$ 197.0771, and $m / z 182.0486$ which corresponded to [M-H-Glc] $]^{-}$, [M$\mathrm{H}-\mathrm{Glc}-\mathrm{CO}]^{-}$, [M-H-Glc-CO $]^{-}$, [M-H-CO-CO $]^{-}$, and $\left[\mathrm{M}-\mathrm{H}-\mathrm{CO}_{2}-\mathrm{CH}_{3}-\mathrm{CO}\right]^{-}$, respectively. Compounds 12, 43, 44, and 49 were tentatively identified by comparing their accurate molecular masses and MS/MS fragment data with literature data $[21,40,41]$.

3.2.4. Triterpenoids. Eight triterpenoids (Figure 3(d)) in LQC were unambiguously or tentatively identified. All of them were derived from Gancao. Glycyrrhizic acid (57) was confirmed by comparing with standards. In negative ion mode, representative compound 57 yielded $\left[\mathrm{M}-\mathrm{H}-\mathrm{H}_{2} \mathrm{O}-\right.$ $\left.\mathrm{CO}_{2}\right]^{-}$at $m / z$ 759.4524, [M-H-GlcA (glucuronic acid)] at $m / z$ 645.4102, [M-H-2GlcA] ${ }^{-}$at $m / z$ 469.3705, [2GlcA$\mathrm{H}]^{-}$at $\mathrm{m} / z$ 351.0809, and [2GlcA-H- $\left.\mathrm{H}_{2} \mathrm{O}-\mathrm{CO}_{2}\right]^{-}$at $\mathrm{m} / z$ 289.0758, as shown in Figure 4(h). Compounds 48, 50, 52, $55,58,59$, and 60 were tentatively identified by comparing their exact molecular masses and MS/MS spectral data with the literature data [51].

3.2.5. Iridoids. Four iridoids (Figure 3(e)) in LQC including iridoid glycosides and secoiridoid glycosides were identified. All of them were derived from Jinyinhua. Loganic acid (5), sweroside (13), and secoxyloganin (20) were unambiguously identified via the standards.

The fragment ${ }^{1,4} \mathrm{~F}$ (fragment generated from the fracture of $1 / 4$ bonds of iridoids) in the negative ion mode was identified as the characteristic fragment ion of iridoid glycosides. Meanwhile, iridoid glycosides would lose the functional groups such as $\mathrm{H}_{2} \mathrm{O}(18 \mathrm{Da}), \mathrm{CO}_{2}(44 \mathrm{Da})$, and glucose $(162 \mathrm{Da})$. Typical compound 5 gave $\left[\mathrm{M}-\mathrm{H}-\mathrm{Glc}-\mathrm{CO}_{2}-\mathrm{H}_{2} \mathrm{O}\right]^{-}$ at $m / z$ 151.0878, [M-H-Glc-2 $\left.\mathrm{CO}_{2}\right]^{-}$at $\mathrm{m} / z$ 125.0712, and $\left[{ }^{1,4} \mathrm{~F}-\mathrm{H}_{2} \mathrm{O}\right]^{-}$at $m / z 93.0423$ [52], as presented in Figure 4(i). Compound $\mathbf{1 0}$ was tentatively identified by comparing its exact molecular mass and MS/MS spectral data with the literature data [19].

3.2.6. Other Types of Compounds. Compounds 1, 2, 11, 14, 15, and 51 were tentatively identified by comparing their exact molecular masses and MS/MS spectral data with the literature data except gallic acid (3), salidroside (6), forsythoside E (7), and amygdalin (33) which were identified via the standards (Figure 3(f)) [12, 53].

3.3. Methodological Validation of the Quantitative Analysis. As shown in Table 3, twelve standards were of good linearity with high correlation coefficient values over 0.9993 . The LODs and LOQs were $0.051-1.71 \mu \mathrm{g} / \mathrm{mL}$ and $0.16-$ $5.69 \mu \mathrm{g} / \mathrm{mL}$, independently. Twelve analytes in sample solution were stable at room temperature within $48 \mathrm{~h}$ with 


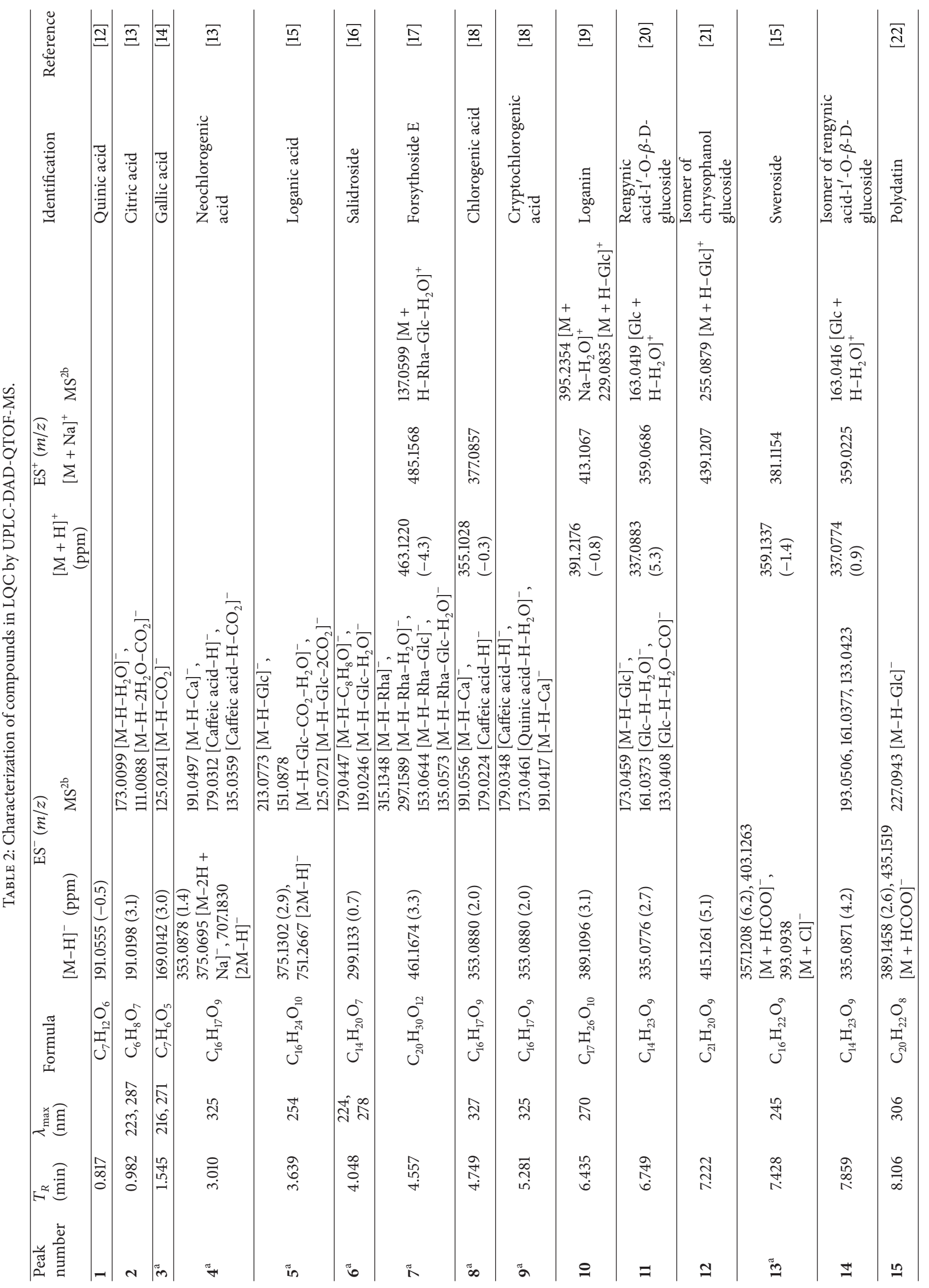




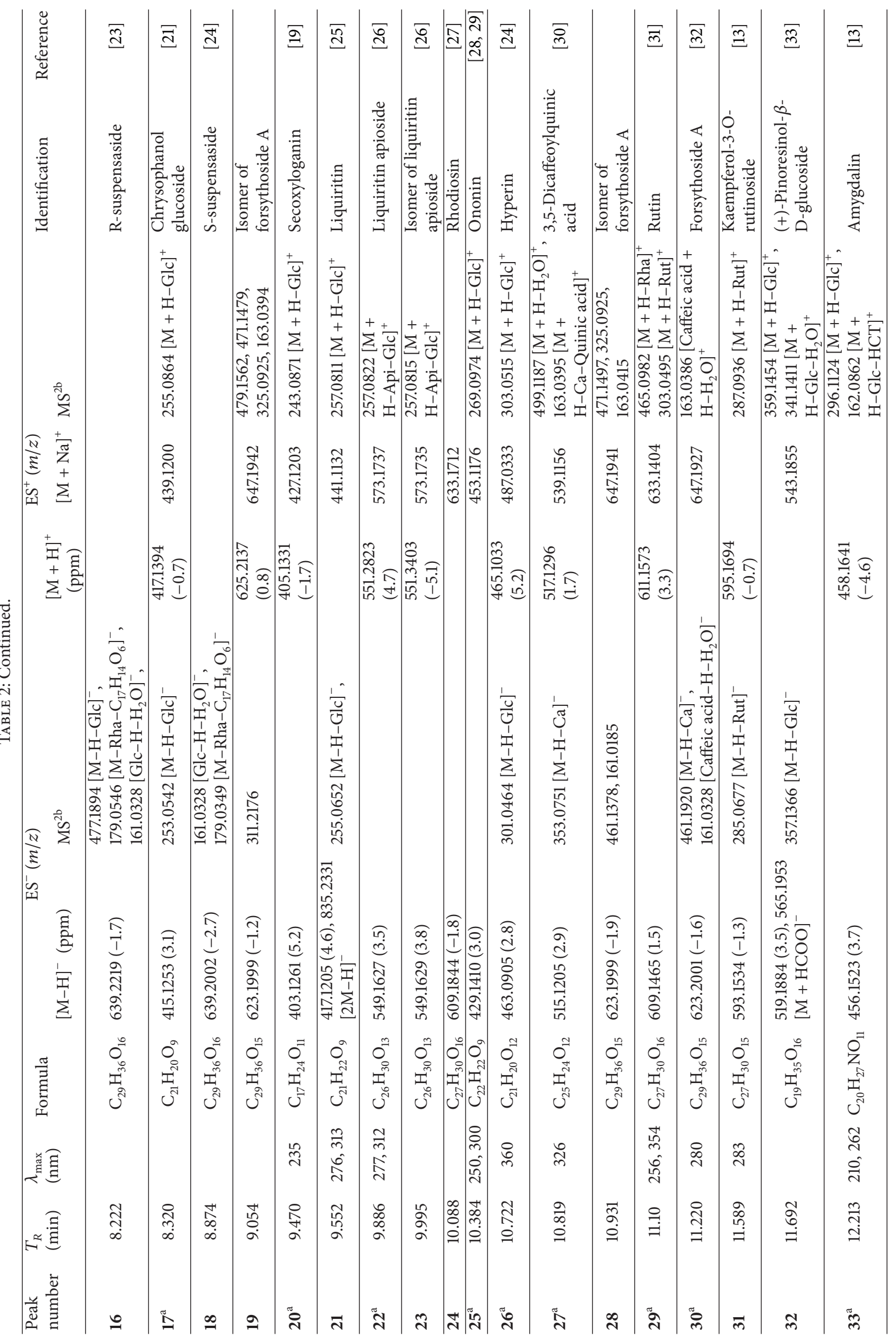




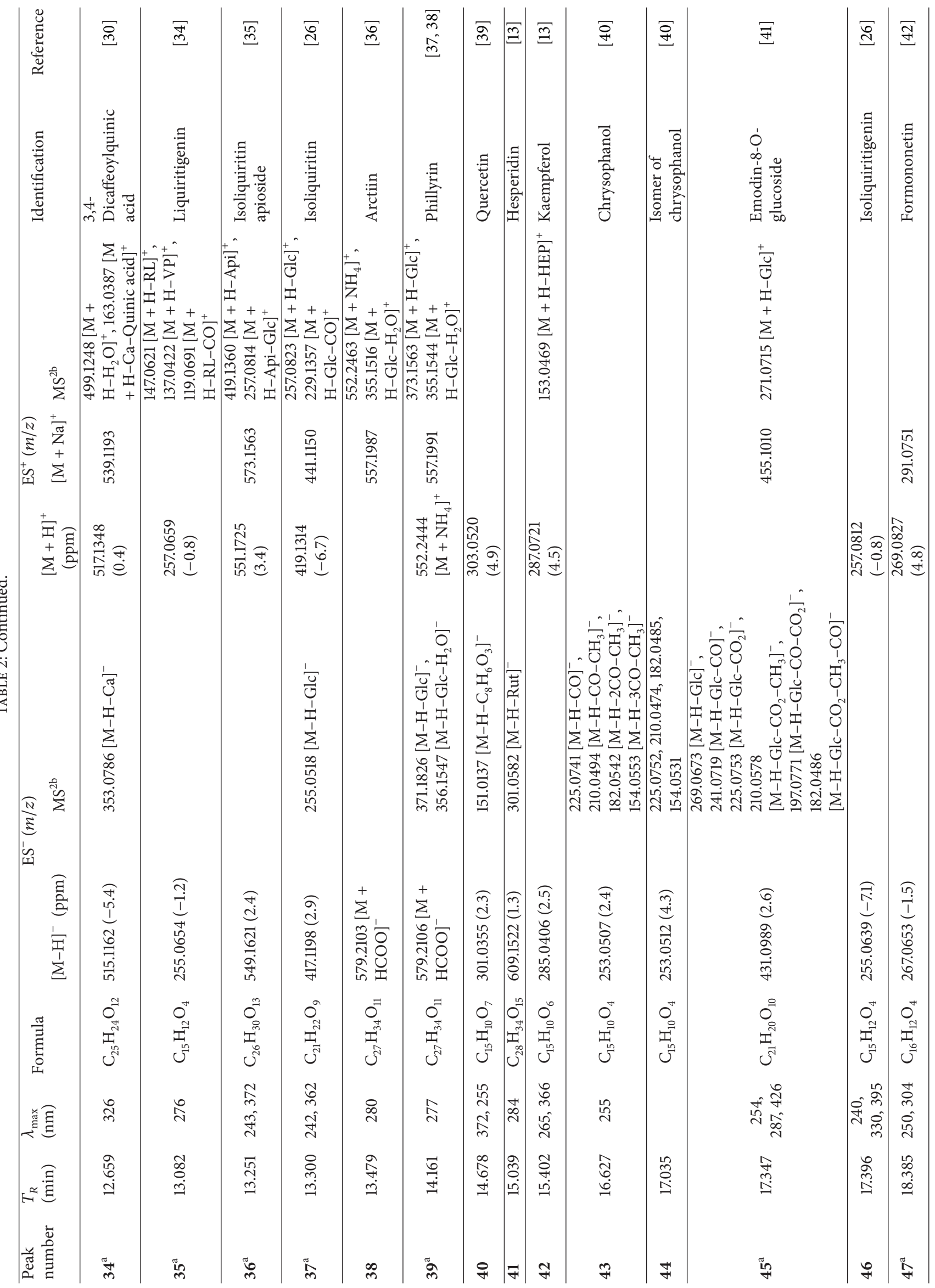




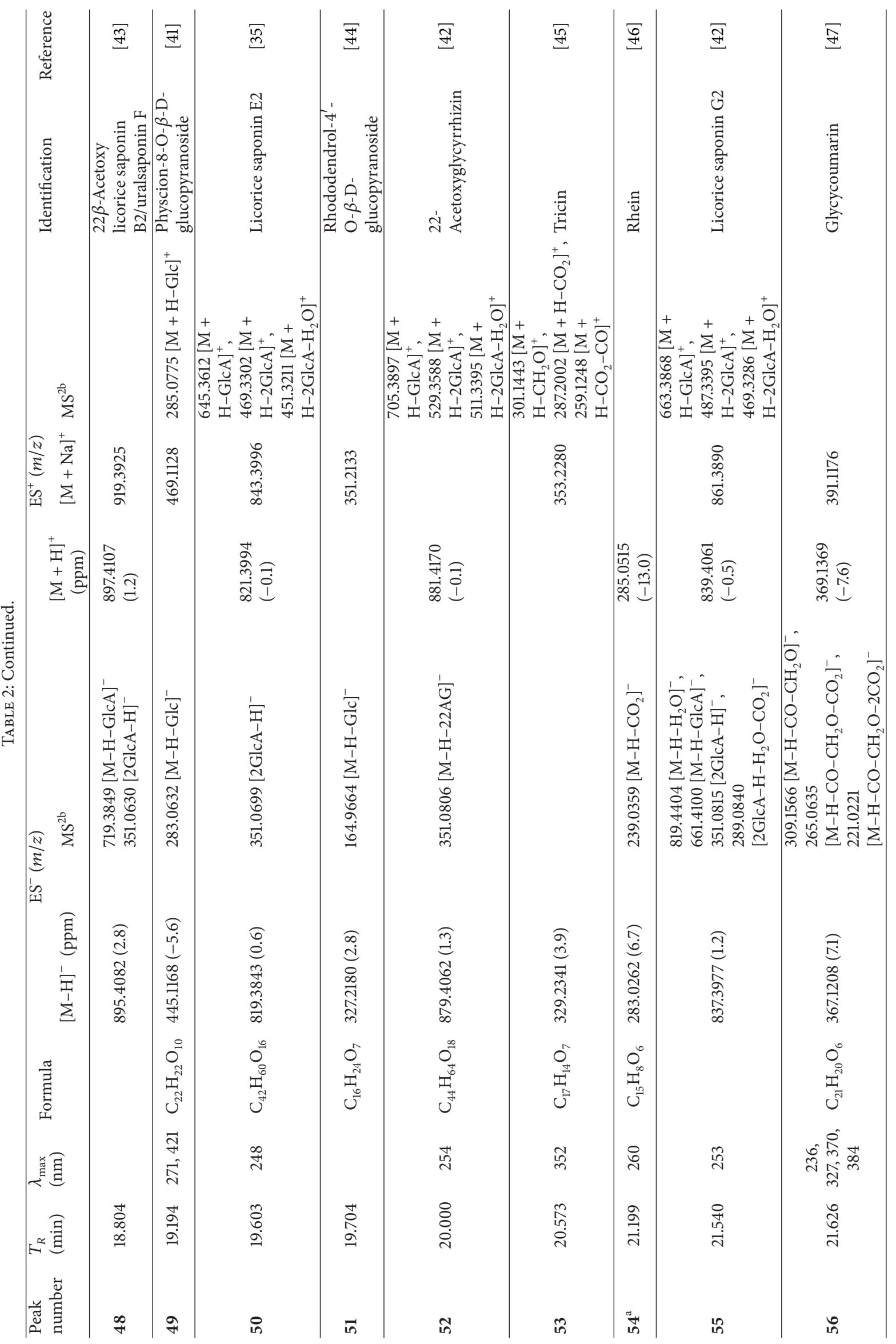




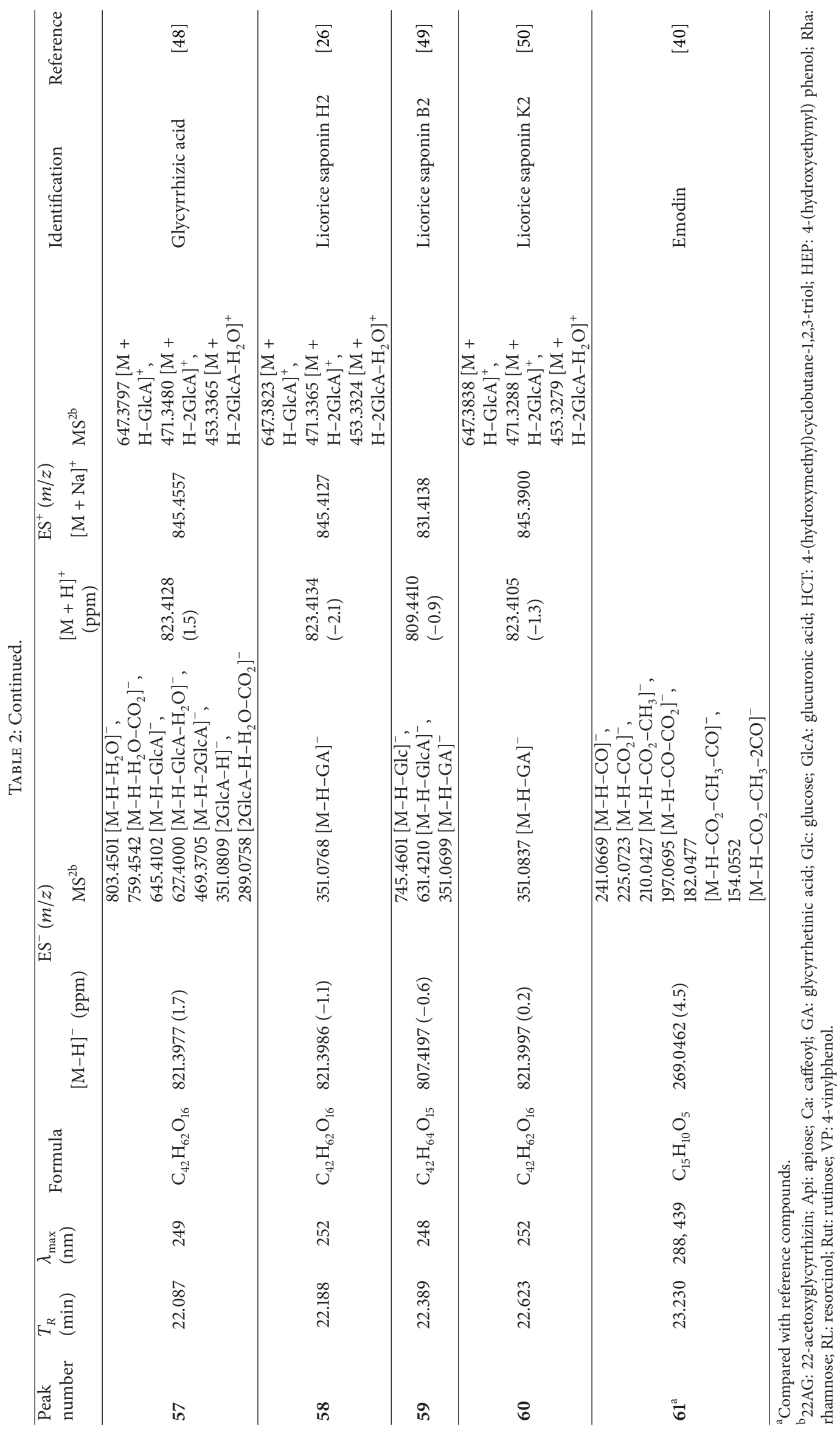




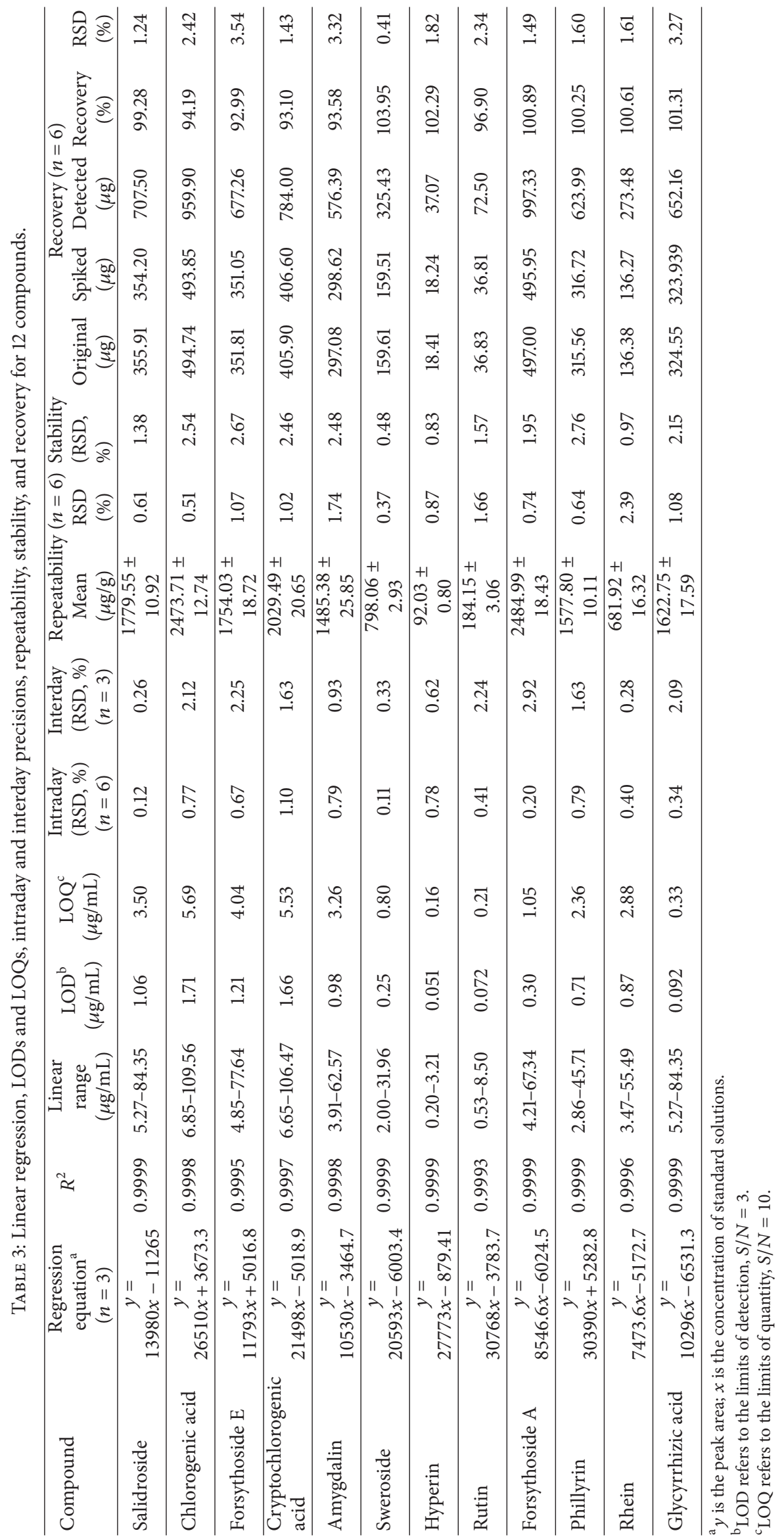







the RSD less than $2.76 \%$. The RSD values of intraday and interday precisions were less than $1.10 \%$ and $2.92 \%$, respectively. The RSD of repeatability was less than $2.39 \%$. The average recovery rates of 12 compounds ranged from $92.99 \%$ to $103.95 \%$ with the RSD less than $3.54 \%$. All the results showed that the assay was satisfactory with high accuracy, good reproducibility, and high sensitivity which were beneficial to the analytical investigation and quality control for LQC.

3.4. Sample Analysis. Twelve representative compounds in 10 batches of LQC were quantified through the developed UPLC-DAD analytical method described above. The results are summarized in Table 4, which showed that the total concentrations of 12 quantitative compounds in different batches of the LQC varied narrowly; moreover, the 12 components differed greatly in their contents, which may be affected by the source of medicinal materials, the quality of the plant material, or the preparation technology. Among them, forsythoside A showed the highest amount (3164.55$2089.22 \mu \mathrm{g} / \mathrm{g})$ followed by amygdalin $(2594.75-1623.14 \mu \mathrm{g} / \mathrm{g})$ and hyperin had the lowest amount at $100.80-62.56 \mu \mathrm{g} / \mathrm{g}$.

\section{Conclusion}

LQC is a commonly used Chinese medical preparation to treat viral influenza. To date, there has not been a systematical and comprehensive study on the chemical profiling and quality control method for LQC. Therefore, an accurate, sensitive, and reliable quality control procedure for LQC is in urgent need to be established. In our study, the chemical profile of LQC was thoroughly and systematically investigated by UPLC-DAD-QTOF-MS for the first time. Sixty-one compounds were unambiguously or tentatively identified. Based on the qualitative analysis, a UPLC-DAD method was established for quantitative analysis of 12 representative compounds in LQC, which has been demonstrated to be effective for the analysis of 10 batches of LQC. This developed method could be applied as an effective quality control procedure for LQC. In addition, this study would be a powerful reference for the identification of similar compounds presented here, such as flavonoids, phenylpropanoids, anthraquinones, triterpenoids, and iridoids by MS spectra.

\section{Conflict of Interests}

The authors declare that there is no conflict of interests regarding the publication of this paper.

\section{Authors' Contribution}

Weina Jia and Chunhua Wang contributed equally to this work.

\section{Acknowledgments}

Financial support from Tianjin Applied Basic and CuttingEdge Technology Research Programs (nos. 13JCZDJC28600 and 13JCYBJC42000), Project of New Drug Discovery Platform (no. 2012ZX09304007), and State Key Development Program for Basic Research of China (“973" Program, no. 2012CB723504) is gratefully acknowledged.

\section{References}

[1] C. Y. Liu, X. Q. Li, and S. Q. Cai, "Research progress on the pharmacological and clinical study of Lianhua Qingwen capsule," Pharmacology and Clinics of Chinese Materia Medica, vol. 26, no. 6, pp. 84-85, 2010.

[2] X. Yi, "The antiviral report of Lianhua Qingwen capsule," The Chinese Health Care, no. 9, pp. 13-14, 2012.

[3] Z.-P. Duan, Z.-H. Jia, J. Zhang et al., "Natural herbal medicine lianhuaqingwen capsule anti-influenza a $(\mathrm{H} 1 \mathrm{~N} 1)$ trial: a randomized, double blind, positive controlled clinical trial," Chinese Medical Journal, vol. 124, no. 18, pp. 2925-2933, 2011.

[4] H. Kiyohara, C. Ichino, Y. Kawamura, T. Nagai, N. Sato, and H. Yamada, "Patchouli alcohol: in vitro direct anti-influenza virus sesquiterpene in Pogostemon cablin Benth," Journal of Natural Medicines, vol. 66, no. 1, pp. 55-61, 2012.

[5] L. Dong, J.-W. Xia, Y. Gong et al., "Effect of Lianhuaqingwen capsules on airway inflammation in patients with acute exacerbation of chronic obstructive pulmonary disease," EvidenceBased Complementary and Alternative Medicine, vol. 2014, Article ID 637969, 11 pages, 2014.

[6] G. Chen, H. M. Guang, L. Li et al., "Biological network analysis on mechanism of Lianhua Qingwen granules/capsules for H1N1 influenza A," Journal of Traditional Chinese Medicine, vol. 55, no. 8, pp. 703-707, 2014.

[7] S. H. Zhao, H. H. Xu, X. Y. Li et al., "TLC and quantitative determination by HPLC for Lianhua Qingwen capsule," Drug Standards of China, vol. 8, no. 1, pp. 55-59, 2007.

[8] Q. F. Qin, "Determination of chlorogenic acid, forsythin, rhein, emodin and chrysophanol in Lianhua Qingwen capsules by HPLC," Chinese Journal of Modern Applied Pharmacy, vol. 31, no. 2, pp. 210-213, 2014.

[9] Y. Ling, Y. Y. Wang, G. T. Chen, and X. Y. Wang, "Simultaneous determination of five components from radixet rhizoma rhei in Lianhua Qingwen capsule by HPLC," China Journal of Chinese Medicine, vol. 27, no. 172, pp. 1157-1158, 2012.

[10] P. Huo, S. Qin, L. H. Huang, and Y. J. Xu, "Simultaneous determination of six effective components in Lianhuaqingwen capsule by micellar electrokinetic capillary chromatography," Journal of Instrumental Analysis, vol. 30, no. 4, pp. 396-400, 2011.

[11] R. Shi, W. J. Jiang, S. Qiao, M. Y. Liu, and Q. Wang, "Determination of nine constituents in Lianhua Qingwen capsules by LC-MS/MS combined with ion switching technology," Chinese Journal of Pharmaceuticals, vol. 42, no. 10, pp. 777-780, 2011.

[12] Y. Ogawa, M. Kawai, A. Kinoshita, and T. Konishi, "Nitrogencontaining compounds from Hemerocallis fulva var. sempervirens," Chemistry of Natural Compounds, vol. 49, no. 6, pp. 991995, 2014.

[13] L. Zhang, L. Zhu, Y. Wang et al., "Characterization and quantification of major constituents of Xue Fu Zhu Yu by UPLC-DADMS/MS," Journal of Pharmaceutical and Biomedical Analysis, vol. 62, pp. 203-209, 2012.

[14] W. Lan, L. Bian, X. Zhao et al., "Liquid chromatography/quadrupole time-of-flight mass spectrometry for identification of in vitro and in vivo metabolites of bornyl gallate 
in rats," Journal of Analytical Methods in Chemistry, vol. 2013, Article ID 473649, 10 pages, 2013.

[15] S. Deng, B. J. West, and C. J. Jensen, "UPLC-TOF-MS characterization and identification of bioactive iridoids in Cornus mas fruit," Journal of Analytical Methods in Chemistry, vol. 2013, Article ID 710972, 7 pages, 2013.

[16] N. Guo, Z. W. Hu, X. X. Fan et al., "Simultaneous determination of Salidroside and its aglycone metabolite p-tyrosol in rat plasma by liquid chromatography-tandem mass spectrometry," Molecules, vol. 17, no. 4, pp. 4733-4754, 2012.

[17] L. H. Jian, Q. Hu, J. Q. Zhong, Q. Meng, K. Wang, and S. Ji, "Determination of forsythoside $\mathrm{E}$ in Tanreqing injection by LCMS/MS," Chinese Journal of Pharmaceutical Analysis, vol. 33, no. 3, pp. 435-438, 2013.

[18] Y.-J. Li, J. Chen, and P. Li, "Identification and quantification of free radical scavengers in the flower buds of Lonicera species by online HPLC-DPPH assay coupled with electrospray ionization quadrupole time-of-flight tandem mass spectrometry," Biomedical Chromatography, vol. 26, no. 4, pp. 449-457, 2012.

[19] Z.-M. Qian, H.-J. Li, P. Li, M.-T. Ren, and D. Tang, "Simultaneous qualitation and quantification of thirteen bioactive compounds in Flos Lonicerae by high-performance liquid chromatography with diode array detector and mass spectrometry," Chemical and Pharmaceutical Bulletin, vol. 55, no. 7, pp. 10731076, 2007.

[20] Y. Liu, Studies on the Chemical Constituents of the Extract with Water from Forsythia Suspensa (Thunb.) Vahl, Shenyang Pharmaceutical University, Shenyang, China, 2003.

[21] H. Q. Jiang, R. Rong, and Q. H. Lv, "Identification of chemical composition in Rhubarb by high performance liquid chromatography with mass spectrometry," Lishizhen Medicine and Materia Medica Research, vol. 22, no. 7, pp. 1075-1076, 2011.

[22] G. Qian, S.-Y. Leung, L. U. Guanghua, and K. S.-Y. Leung, "Differentiation of Rhizoma et Radix Polygoni Cuspidati from closely related herbs by HPLC fingerprinting," Chemical and Pharmaceutical Bulletin, vol. 54, no. 8, pp. 1179-1186, 2006.

[23] H. Guo, A.-H. Liu, L. Li, and D.-A. Guo, "Simultaneous determination of 12 major constituents in Forsythia suspensa by high performance liquid chromatography-DAD method," Journal of Pharmaceutical and Biomedical Analysis, vol. 43, no. 3, pp. 1000-1006, 2007.

[24] Y. Cui, Q. Wang, X. Shi, X. Zhang, X. Sheng, and L. Zhang, "Simultaneous quantification of 14 bioactive constituents in Forsythia suspensa by liquid chromatography-electrospray ionisation-mass spectrometry," Phytochemical Analysis, vol. 21, no. 3, pp. 253-260, 2010.

[25] H. Liu, J. Su, X. Liang et al., "Identification and determination of the major constituents in traditional Chinese medicine Longdan Xiegan Pill by HPLC-DAD-ESI-MS," Journal of Pharmaceutical Analysis, vol. 1, no. 1, pp. 1-7, 2011.

[26] Q. W. Yin, P. Wang, A. H. Zhang, H. Sun, X. H. Wu, and X. Wang, "Ultra-performance LC-ESI/quadrupole-TOF MS for rapid analysis of chemical constituents of Shaoyao-Gancao decoction," Journal of Separation Science, vol. 36, no. 7, pp. 12381246, 2013.

[27] J. L. Huo, J. H. Wang, Z. J. Wu, and G. L. Zhang, "Analysis of chemical constituents of Rhodiola crenulata using high performance liquid chromatography-mass spectrometry," Natural Product Research and Development, vol. 24, pp. 1405-1407, 2012.

[28] J. Dong, Y. Zhu, X. Gao, Y. Chang, M. Wang, and P. Zhang, "Qualitative and quantitative analysis of the major constituents in Chinese medicinal preparation Dan-Lou tablet by ultra high performance liquid chromatography/diode-array detector/quadrupole time-of-flight tandem mass spectrometry," Journal of Pharmaceutical and Biomedical Analysis, vol. 80, pp. 50-62, 2013.

[29] M. I. Kusaikin, A. M. Zakharenko, S. P. Ermakova et al., "Deglycosylation of isoflavonoid glycosides from Maackia amurensis cell culture by $\beta$-D-glucosidase from Littorina sitkana hepatopancrease," Chemistry of Natural Compounds, vol. 47, no. 2, pp. 197-200, 2011.

[30] C. P. Wan, Y. Y. Yu, S. R. Zhou, S. G. Tian, and S. W. Cao, "Isolation and identification of phenolic compounds from Gynura divaricata leaves," Pharmacognosy Magazine, vol. 7, no. 26, pp. 101-108, 2011.

[31] X. Yao, G. S. Zhou, Y. P. Tang et al., "A UPLC-MS/MS method for qualification of quercetin-3-O- $\beta$-D- glucopyranoside $(4 \rightarrow 1)-\alpha$-L- rhamnoside in rat plasma and application to pharmacokinetic studies," Molecules, vol. 18, no. 3, pp. 30503059, 2013.

[32] H. Guo, A.-H. Liu, M. Ye, M. Yang, and D.-A. Guo, "Characterization of phenolic compounds in the fruits of Forsythia suspensa by high-performance liquid chromatography coupled with electrospray ionization tandem mass spectrometry," Rapid Communications in Mass Spectrometry, vol. 21, no. 5, pp. 715729, 2007.

[33] G. L. Yan, A. H. Zhang, H. Sun et al., "An effective method for determining the ingredients of Shuanghuanglian formula in blood samples using high-resolution LC-MS coupled with background subtraction and a multiple data processing approach," Journal of Separation Science, vol. 36, no. 19, pp. 31913199, 2013.

[34] M. Ye, W. Z. Yang, K. D. Liu et al., "Characterization of flavonoids in Millettia nitida var. hirsutissima by HPLC/DAD/ESI-MS ", Journal of Pharmaceutical Analysis, vol. 2, no. 1, pp. 35-42, 2012.

[35] W.-J. Miao, Q. Wang, T. Bo et al., "Rapid characterization of chemical constituents and rats metabolites of the traditional Chinese patent medicine Gegen-Qinlian-Wan by UHPLC/DAD/qTOF-MS," Journal of Pharmaceutical and Biomedical Analysis, vol. 72, pp. 99-108, 2013.

[36] F. He, D.-Q. Dou, Y. Sun, L. Zhu, H.-B. Xiao, and T.-G. Kang, "Plasma pharmacokinetics and tissue distribution of arctiin and its main metabolite in rats by HPLC-UV and LC-MS," Planta Medica, vol. 78, no. 8, pp. 800-806, 2012.

[37] Q. Su, Q.-F. Liu, Y. Wang, K.-S. Bi, and G.-A. Luo, "Rapid and sensitive assay of the main components in Shuanghuanglian preparations by UPLC-TOF-MS," Chemical Research in Chinese Universities, vol. 25, no. 1, pp. 122-124, 2009.

[38] Q. Wu, M.-H. Bang, J.-G. Cho et al., "Phenolic compounds from the roots of Brassica rapa ssp. campestris," Chemistry of Natural Compounds, vol. 49, no. 5, pp. 852-856, 2013.

[39] N. Li, C. H. Liu, S. Q. Mi et al., "Simultaneous determination of oleanolic acid, p-coumaric acid, ferulic acid, kaemperol and quercetin in rat plasma by LC-MS-MS and application to a pharmacokinetic study of oldenlandia diffusa extract in rats," Journal of Chromatographic Science, vol. 50, no. 10, pp. 885-892, 2012.

[40] J. Z. Zhang, W. Y. Gao, Z. Liu, and Z. D. Zhang, "Identification and simultaneous determination of twelve active components in the methanol extract of traditional medicine Weichang'an pill by HPLC-DAD-ESI-MS/MS," Iranian Journal of Pharmaceutical Research, vol. 12, no. 1, pp. 15-24, 2013. 
[41] Z. T. Liang, H. B. Chen, Z. L. Yu, and Z. Z. Zhao, "Comparison of raw and processed Radix Polygoni Multiflori (Heshouwu) by high performance liquid chromatography and mass spectrometry," Chinese Medicine, vol. 5, article 29, 2010.

[42] W.-W. Huang, M.-Y. Wang, H.-M. Shi et al., "Comparative study of bioactive constituents in crude and processed Glycyrrhizae radix and their respective metabolic profiles in gastrointestinal tract in vitro by HPLC-DAD and HPLC-ESI/MS analyses," Archives of Pharmacal Research, vol. 35, no. 11, pp. 1945-1952, 2012.

[43] W. W. Tao, J. A. Duan, J. M. Guo et al., "Simultaneous determination of triterpenoid saponins in dog plasma by a validated UPLC-MS/MS and its application to a pharmacokinetic study after administration of total saponin of licorice," Journal of Pharmaceutical and Biomedical Analysis, vol. 75, pp. 248-255, 2013.

[44] W. Zhao, Studies on the Chemical Constituents of Ephedra sinica, Peking Union Medical College, Beijing, China, 2009.

[45] J. Sun, Y. D. Yue, F. Tang, X. F. Guo, and J. Wang, "Flavonoids from the leaves of Neosinocalamus affinis," Chemistry of Natural Compounds, vol. 49, pp. 822-825, 2013.

[46] M. L. Hou, L. W. Chang, C. H. Lin, L. C. Lin, and T. H. Tsai, "Determination of bioactive components in Chinese herbal formulae and pharmacokinetics of rhein in rats by UPLCMS/MS," Molecules, vol. 19, pp. 4058-4075, 2014.

[47] L. Zhou, Y.-P. Tang, L. Gao, X.-S. Fan, C.-M. Liu, and D.-K. $\mathrm{Wu}$, "Separation, characterization and dose-effect relationship of the PPAR $\gamma$-activating bio-active constituents in the chinese herb formulation 'San-ao decoction,' Molecules, vol. 14, no. 10, pp. 3942-3951, 2009.

[48] S. Tsuruda, T. Sakamoto, and K. Akaki, "Simultaneous determination of twelve sweeteners and nine preservatives in foods by solid-phase extraction and LC-MS/MS," Shokuhin Eiseigaku Zasshi, vol. 54, no. 3, pp. 204-212, 2013.

[49] I. Kitagawa, K. Hori, T. Taniyama, J.-L. Zhou, and M. Yoshikawa, "Saponin and sapogenol. XLVII. On the constituents of the roots of Glycyrrhiza uralensis Fisher from Northeastern China (1). Licorice-saponins A3, B2, and C2," Chemical and Pharmaceutical Bulletin, vol. 41, no. 1, pp. 43-49, 1993.

[50] I. Kitagawa, K. Hori, M. Sakagami, J.-L. Zhou, and M. Yoshikawa, "Saponin and sapogenol. XLVIII. On the constituents of the roots of Glycyrrhiza uralensis FISCHER from Northeastern China. (2). Licorice-saponins D3, E2, F3, G2, H2, J2, and K2," Chemical and Pharmaceutical Bulletin, vol. 41, no. 8, pp. 1337-1345, 1993.

[51] X.-D. Yang, X.-Y. Tang, and L. Sang, "Rapid identification of micro-constituents in monoammonium glycyrrhizinate raw materials by high-pressure solid phase extraction-high performance liquid chromatography-mass spectrometry," China Journal of Chinese Materia Medica, vol. 37, no. 22, pp. 3416-3421, 2012.

[52] C.-M. Li, X.-M. Liang, and X.-Y. Xue, "Electrospray ionization quadrupole time-of-flight tandem mass spectrometry of iridoid glucosides in positive ion mode," Chemical Journal of Chinese Universities, vol. 34, no. 3, pp. 567-572, 2013.

[53] F. Wang, J. Y. Zhang, Q. Wang, Y. Liu, Z. J. Wang, and J. Q. $\mathrm{Lu}$, "Identification of phenolic acids from Kudiezi injection by HPLC-HR-MS n," Central South Pharmacy, vol. 11, no. 8, pp. 561-565, 2013. 



\section{Carbohydrate} Chemistry



The Scientific World Journal
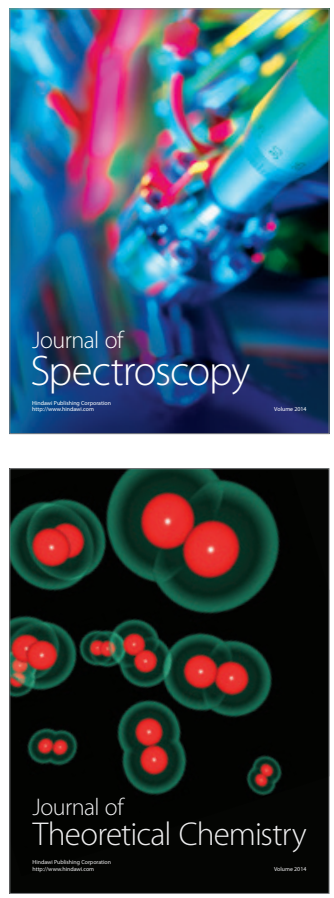


Submit your manuscripts at

http://www.hindawi.com

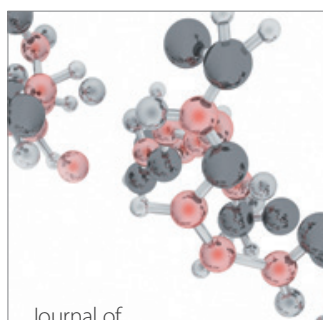

Analytical Methods

in Chemistry

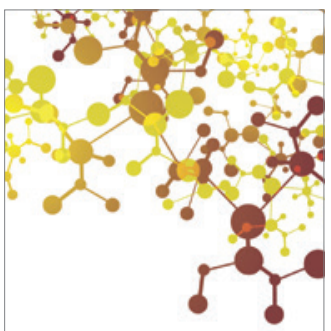

Journal of

Applied Chemistry

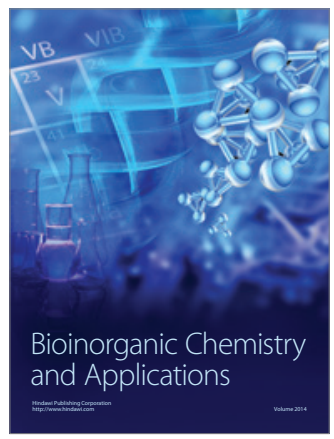

Inorganic Chemistry
